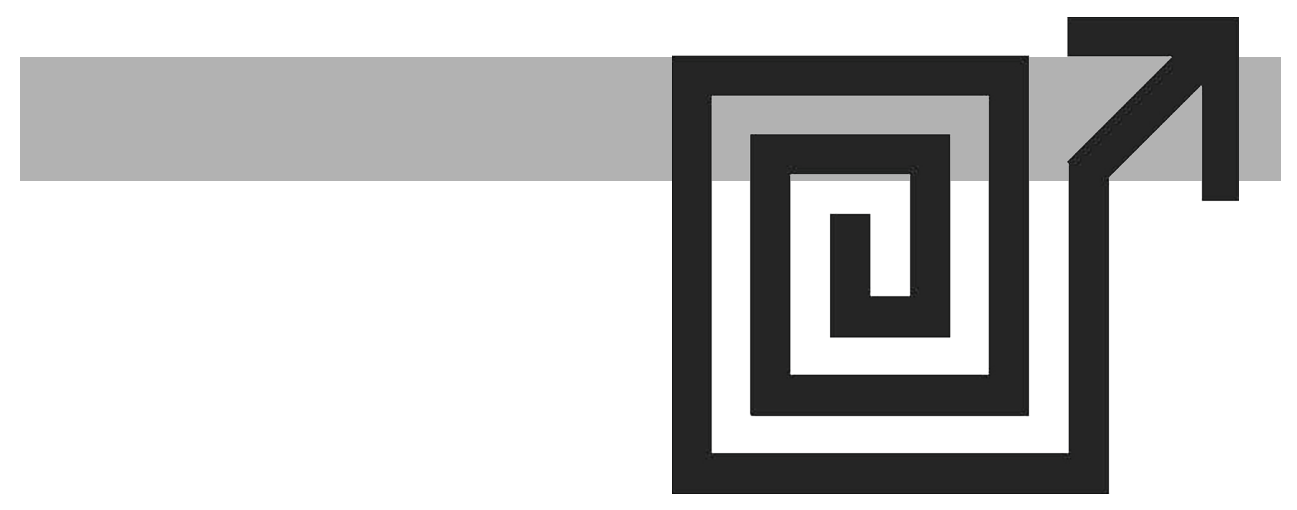

In Memoriam

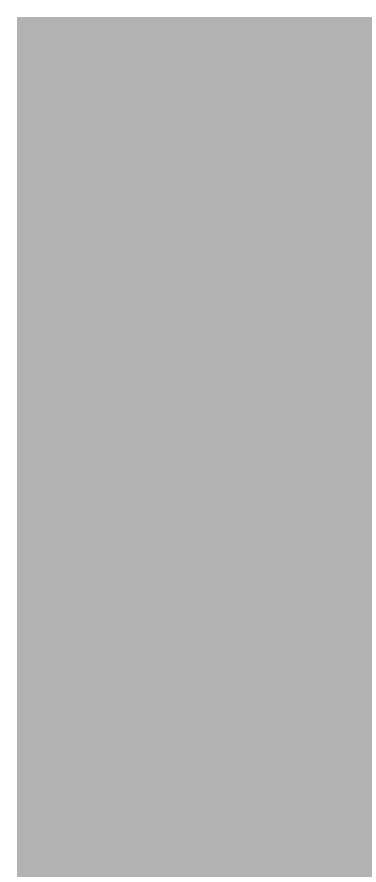





\section{AMEDEO G. CONTE: REGLAS CONSTITUTIVAS, VALIDEZ DEÓNTICA, SEMIÓTICA NORMATIVA}

\section{AMEDEO G. CONTE: CONSTITUTIVE RULES, DEONTIC VALIDITY, NORMATIVE SEMIOTICS}

\section{Carlos Alarcón Cabrera}

Universidad Pablo de Olavide, Sevilla, España

calacab@upo.es

Resumen: Se lleva a cabo un recorrido analítico del pensamiento filosófico de Amedeo Conte, filósofo del derecho recientemente fallecido. Conte es el discípulo de Bobbio que de un modo más certero profundizó en el estudio del impacto de la filosofía analítica en el universo normativo. Lo hizo a partir de los principales conceptos avanzados por Ludwig Wittgenstein, desarrollados a su vez por el discípulo, albacea y sucesor de éste, Georg H. von Wright, autor del principal sistema estándar de lógica deóntica.

Abstract: This paper analyze the philosophical thinking of Amedeo Conte, legal philosopher recently death. Conte is the disciple of Bobbio that deepened in a very certain way in the study of the impact of the analytical philosophy in the normative universe. He did it from the main concepts of Ludwig Wittgenstein, developed specially by the disciple, executor and successor of him, Georg H. von Wright, author of the main standard system of deontic logic.

\section{Los precedentes y presuposiciones de la metalógica deóntica de Conte: la influencia de von Wright}

Amedeo Conte falleció a los 84 años el 17 de mayo de 2019. Su obra constituyó uno de los más logrados intentos de trasladar las aportaciones de la filosofía analítica al ámbito del campo normativo. Discípulo de Bobbio, desarrolló las clarificadoras tesis de su maestro construyendo una potente lógica del lenguaje normativo que facilitó la evolución de los sistemas de lógica deóntica diseñados a partir del sistema estándar de lógica deóntica (SDL) de von Wright de 1951. Y asimismo profundizó enriquecedoramente en el concepto de "regla constitutiva" del propio maestro de von Wright, Lud- 
wig Wittgenstein, de quien también fue su principal traductor al idioma italiano y uno de sus mejores exégetas.

La expresión "Lógica Deóntica" fue usada por primera vez, con su significado actual, por Georg H. von Wright, cuando, junto a los conceptos modales aléticos (necesidad, posibilidad, contingencia; conceptos estudiados por la lógica modal), a los conceptos modales existenciales (universalidad, existencia, vaciedad; conceptos estudiados por la teoría de la cuantificación) y a los conceptos modales epistémicos (lo verificado, lo indeterminado, lo falsado), mencionó los conceptos modales deónticos: lo obligatorio, lo permitido, lo prohibido (von Wright, 1951). Desde entonces, el término "deóntico" ha ido haciéndose común en el léxico filosófico. En particular, como resalta Mazzarese, con una acepción pragmática y con una acepción semántica: a) Pragmaticamente, como sinónimo de 'directivo', 'preceptivo', 'prescriptivo', 'normativo', en oposición a 'descriptivo', 'declarativo', 'asertivo'; b) Semánticamente, en el sentido de "concerniente al deber ser", para designar lo que constituye la esfera del deber ser o lo que describe la esfera del deber ser (Mazzarese, 1989).

En su trabajo de 1951, titulado precisamente Lógica deóntica (Deontic Logic), von Wright construye por primera vez una lógica formal elemental de las modalidades deónticas (obligatorio, permitido, prohibido), una lógica deóntica. Sus presupuestos son los siguientes: $1^{\circ}$ ) Las cosas a las que llamamos obligatorias, permitidas o prohibidas son actos, entendidos no en sentido individual, sino como propiedad que lo califica (robo, pago de impuestos, conducción de un vehículo,...); $2^{\circ}$ ) Respecto a quien realiza el acto (el agente), hay un valor de ejecución del acto y un valor de no ejecución del acto, análogos a los valores clásicos de la verdad y la falsedad. Desde 1951, von Wright ha dedicado cientos de artículos y libros a perfeccionar su SDL. Es por ello que el análisis de su evolución teórica sirve para ofrecer un panorama diacrónico de las diferentes lógicas normativas construidas desde entonces.

La aportación más conocida (y reconocida) de von Wright a la lógica deóntica y a la teoría de la acción es posiblemente Norma y acción (1963), libro además muy influyente en la teoría y filosofía jurídica de las últimas decadas, pero en el que sin embargo no aclara su opción ontológica. Las normas, dirá entonces von Wright, no son entidades extralingüísticas, simples regularidades sociales de comportamiento; pero tampoco entidades lingüísticas. Von Wright no afirma claramente ni que sean enunciados lingüísticos (situados, por consiguiente, a un nivel sintáctico), ni que sean proposiciones lingüísticas (a un nivel semántico), ni que sean actos de enunciación lingüística (a un nivel pragmático).

Así, además de descartar que las normas sean entidades extralingüísticas ("las normas dependen del lenguaje [...]. Su existencia presupone necesariamente el uso del lenguaje"), von Wright también parece negar que sean enunciados deónticos ("deberemos distinguir entre la norma y la formulación normativa. La formulación normativa es el signo o símbolo (las palabras) usadas al enunciar (formular) la norma"), que sean proposiciones deónticas ("es evidente que a algunas normas no se les puede dar el nombre de 'proposiciones' [...]. Las normas no tienen por qué llamarse ni la referencia ni incluso el sentido o significado de la correspondiente formulación normativa") y que sean enunciaciones deónticas de enunciados ("la norma es algo distinto del hecho de dar a conocer a los sujetos normativos su carácter, 
contenido y condiciones de aplicación, lo cual es un eslabón esencial en el (o parte del) proceso a través del cual la norma se origina o cobra existencia (ser), pero no es la norma en sí misma").

En Norma y acción von Wright presenta un sistema de modalidades deónticas con el objetivo de superar la unilateralidad argumental de los operadores monádicos del SDL. Con los operadores diádicos se expresan, implícita o explícitamente, relaciones entre dos argumentos que constituían el antecedente y el consecuente de la implicación normativa, de la implicación deóntica.

En el sistema diádico, las acciones dejan de ser obligatorias en sí mismas, y es preciso determinar en qué condiciones lo son, en qué universo normativo o fáctico lo son. Este sistema diádico se componía de tres estratos: (i) la lógica proposicional tradicional, basada en el estudio formal de las expresiones $p, q, \ldots$; (ii) la lógica del cambio, basada en el estudio formal de las expresiones $T$, en la que el suceso descrito por "pTq" es una transformación de un estado inicial de cosas descrito por "p" a un estado final de cosas descrito por "q"; (iii) la lógica de la acción, basada en el estudio formal de las expresiones $\mathrm{df}$, en la que "d(-pTp)" significa que un agente, en una determinada ocasión, provoca el estado de cosas descrito por " $p$ ", inexistente hasta entonces; y en la que "f(-pTp)" significa que un agente, en una determinada ocasión, se abstiene de provocar el estado de cosas descrito por " $p$ ".

La teoría lógica de la acción condicionada constituía una extensión de la lógica de la acción. Introducía el símbolo / , de forma que la expresión "/" elemental de "(pTp)/ (qTq)" describiera una acción genérica que es ejecutada por un agente de forma que en una determinada ocasión en la que el estado de cosas descrito por "q" se da y permanece independientemente de la acción, el agente impide que desaparezca el estado descrito por "p". "O(pTp)/ (qTq)" es un mandato, cuyo contenido es la acción descrita por "d(pTp)", y cuya condición de aplicación es el cambio descrito por "pTp \& qTq".

En 1968, von Wright escribe Deontic Logic and the Theory of Conditions, donde deja de considerar la lógica deóntica como directamente análoga a la lógica modal, y donde pasa a considerarla un apartado de la "lógica de las condiciones suficientes y necesarias", de tal forma que afirmar que algo debe ser equivale a afirmar que algo es condición necesaria de alguna otra cosa.

En este sistema de lógica condicional, la noción de condición necesaria se explica así: "la verdad de la proposición "p" es condición necesaria de la verdad de la proposición "q"". Su representación formal puede ser "Nc(p,q)" o "N(q --> p)".

En efecto, decir que " $p$ " es condición necesaria de "q" significa que si "-p", entonces "-q", o, asimismo, que si " $q$ ", entonces necesariamente " $p$ ". En términos de condición necesaria, el operador deóntico "O" puede ser definido así: "Op $=N c(p, I)$ ". Que algo debe ser el caso significa que la cosa en cuestión es una condición necesaria de otra determinada cosa (o estado de cosas) "I", que se presupone en el contexto. "I" no es una variable, sino una constante proposicional.

Por su parte, la noción de condición suficiente se explica así: "la verdad de la proposición que " $p$ " es una condición suficiente de la verdad de la proposición que "q"”. Su representación formal puede ser "Sc(p,q)" o "S(q --> p)". 
En efecto, decir que "p" es condición suficiente de "q" significa que si "-q", entonces "-p", o, asimismo, que si " $p$ ", entonces necesariamente "q". "Sc(p,q)" equivale a "Sc(-q,-p)", a "Nc(q,p)" y a "Nc(-p,-q)". En términos de condición suficiente, el operador deóntico "P" puede ser definido así: "Op = Nc(p,l)". Que algo debe ser el caso significa que la cosa en cuestión es una condición suficiente de otra determinada cosa (o estado de cosas) "I", que se presupone en el contexto.

Sin arrepentirse de su concepción de la lógica deóntica como fragmento de la teoría lógica modal de las condiciones necesarias y suficientes, concepción que le había dirigido hacia un enfoque instrumentalista de la lógica de las normas, von Wright se centró pocos años después (Deontic Logic Revisited, 1973) en la distinción, hasta entonces poco estudiada, entre Sein-Sollen (deber ser) y Tun-Sollen (deber hacer), entre las normas que establecen que determinada cosa debe o puede o no debe ser el caso, y las normas que establecen que alguien debe o puede o no debe hacer determinada cosa.

Esta distinción provocaba una alternativa básica en relación con la cuestión de la naturaleza de la lógica deóntica. Von Wright resaltó que la única lógica deóntica construida a partir de la lógica de la acción se había fundado en interpretaciones de las normas como enunciados descriptivos que acompañan a los operadores deónticos ("es obligatorio que las cosas se den", "está permitido que las cosas se den", "está prohibido que las cosas se den"). Existiría entonces una lógica deóntica inexplorada, basada en la conjunción de operadores deónticos y verbos de acción, en la que las variables representarían esquemáticamente frases verbales ("es obligatorio hacer x", "está permitido hacer x", "está prohibido hacer $\mathrm{x} "$ ).

La distinción entre Sein-Sollen y Tun-Sollen es retomada y reformulada posteriormente por von Wright al diferenciar entre: (i) el "deber técnico" ("must"), conforme al cual las cosas deben ser hechas para que otras cosas se consigan, y que suele ser elíptico, suele referirse implícitamente a un fin que no se conseguirá si lo que debe (técnicamente) ser no es; (ii) el "deber deóntico" ("ought"), que procede directamente de una norma, y que es categórico, no es un medio sino un fin en sí mismo.

En On the Logic of Norms and Actions (1981), von Wright cuestiona la idea de que los términos deónticos se refieren a categorías de acciones y no a acciones individuales, algo que decidió en Deontic Logic y que comenzó a matizar en Norma y acción. Y la relaciona con la supuesta interdefinibilidad de los operadores deónticos y la consiguiente imposibilidad de admitir normas contradictorias.

Una acción individual (act-individual) se puede esquematizar diciendo que el agente a hace "p" en la ocasión o. Para identificarla correctamente, no basta con concretar a y o, ya que un agente puede realizar más de una acción en una misma ocasión, por lo que la acción individual, por sí misma, no proporciona datos definitivos sobre su contenido; es necesario aludir a la acción genérica (actcategory) "p". Por ello, en las categorías deónticas cuentan tanto las acciones individuales como las acciones genéricas. Si una acción genérica es obligatoria, está permitida, o está prohibida (la categoría deóntica aparece aquí como operador), la realización u omisión de la acción genérica por parte de un individuo presupone que la acción individual tiene la "propiedad" de ser obligatoria, de estar permitida o de estar prohibida (por el 
contrario, la categoría deóntica aparece aquí como predicado).

Esta forma de ambivalencia de las categorías deónticas (una misma categoría deóntica se usa como operador cuando hace referencia a acciones genéricas, y como predicado cuando hace referencia a acciones individuales) provoca, a juicio de von Wright, importantes consecuencias. Predicar de una acción individual que está permitida debe significar que la acción se incluye dentro de una categoría de acciones genéricas permitidas. En este sentido, de la permisión de un determinado tipo de acciones genéricas podemos inferir la no-prohibición de tales acciones y la no-obligatoriedad de su omisión. Pero si concebimos las categorías deónticas como predicados de acciones individuales no es posible la interdefinibilidad: una misma acción individual puede a la vez ser obligatoria y estar prohibida. Por lo tanto, sólo si consideramos las categorías deónticas como operadores de acciones genéricas hay incompatibilidad entre la obligatoriedad y la prohibición de una misma categoría de acciones. Ni el principio de no contradicción ni la interdefinibilidad de los operadores deónticos se dan como tales en una lógica deóntica que no relacione acciones genéricas, sino acciones individuales.

En Normas, verdad y lógica (1982), von Wright expone su posición definitiva sobre el contenido, implicaciones y presuposiciones de la lógica deóntica. Concibe las leyes de la lógica deóntica como "principios de legislación racional”, y utiliza como ficción (y, por consiguiente, sin adherirse a ella) la idea de que las normas expresan la voluntad de la autoridad legislativa soberana, de que las normas forman un sistema en tanto que proceden de una voluntad ordenadora cuyo criterio de ra- cionalidad ha de consistir en el hecho de que los estados de cosas queridos por el legislador sean (o, al menos, puedan ser) lógicamente posibles.

Aunque, en rigor, no hay una lógica de las normas, del deber ser, porque las normas no son ni verdaderas ni falsas, von Wright sugiere ahora el estudio de una lógica normativa bajo la condición de presuponer que las normas se pueden juzgar según su racionalidad. Resulta así imprescindible analizar los requisitos de racionalidad que debe "satisfacer" una actividad nomothética ("norm-giving activity", actividad de "dar normas", de "poner normas").

Conceptos como el de coherencia normativa (autocoherencia de una norma y coherencia entre las normas) y como el de implicación normativa no se asumen como conceptos propiamente lógicos, sino como conceptos relativos a la racionalidad de la voluntad legisladora. Las tautologías de la lógica deóntica aparecen así como principios de legislación racional (praxeológica), y la actividad judicial de subsunción normativa no es vista ya como una inferencia lógico-normativa, sino como una labor creativa, como un acto nomothético.

En conclusión, las normas no son apofánticas, de ellas no se predica la verdad ni la falsedad, pero si atendemos al criterio de la racionalidad del legislador podemos dotar de significado lógico a la contradicción normativa y a la implicación normativa. Ahora bien, como resalta von Wright, contradicción normativa e implicación normativa son categorías propiamente lógicas, no ontológicas, son categorías que no se expresan en términos ontológicos de contradicción e implicación existencial. Los sistemas de lógica deóntica sólo son modelos ideales que no representan 
adecuadamente estructuras normativas existentes. "Si existen dos normas en conflicto, lo cual puede suceder, es preciso que el legislador modifique la legislación. El lógico no puede ayudarle".

\section{La lingüisticidad del derecho}

Si aceptamos que la experiencia jurídica es también una experiencia normativa, entonces debemos aceptar que el derecho se compone de normas. Pero, ¿pertenecen o no realmente las normas al lenguaje?, ¿son entidades lingüísticas o entidades no lingüísticas? En caso de respuesta afirmativa, ¿qué clase de entidades lingüísticas son? Conte recupera estas preguntas cruciales de la fiIosofía jurídica analítica, que había planteado Bobbio, y ofrece un abanico amplio de respuestas y reflexiones alrededor de ellas.

La respuesta afirmativa a la primera de las cuestiones planteadas fue claramente explicada por Norberto Bobbio, para quien las normas son "proposiciones prescriptivas", son entidades lingüísticas prescriptivas. Toda norma, dice Bobbio, posee una estructura lingüística que puede ser "Ilenada de los más diversos contenidos". Así como la estructura lingüística descriptiva "A es B" es válida para infinitas proposiciones descriptivas ("El mar es azul", "La luna es redonda", "El alumno es aplicado", "El hombre es mortal",.....), y la estructura lingüística valorativa "Cuando es A, me gusta que sea B" es válida para infinitas proposiciones valorativas ("Cuando amanece, me gusta que llueva", "Cuando actuamos justamente, me gusta que seamos recompensados",.....), la estructura lingüística prescriptiva "Si es $A$, debe ser B" es válida para infinitas normas, para infinitas proposiciones prescriptivas ("Si alguien comete asesinato, debe permanecer en prisión treinta años", "Si alguien comete homicidio, debe permanecer en prisión veinte años", "Si no has respetado el semáforo en rojo, debes pagar una multa de 10000 pts.",.....) (Bobbio, 1962).

Es decir, las normas no son proposiciones descriptivas (las normas no se limitan a transmitir una información), ni son proposiciones valorativas (las normas tampoco se limitan a expresar juicios de valor), sino que son proposiciones prescriptivas: tratan de influir en el comportamiento de sus destinatarios para que éstos actúen de acuerdo con lo que las normas estipulan.

Sin embargo, aunque sean proposiciones prescriptivas, las normas jurídicas tienen una parte descriptiva. Cada norma relaciona un supuesto de hecho ("Si es A ...") con una consecuencia jurídica ("... debe ser B"): el supuesto de hecho consiste en la descripción de una hipótesis; la consecuencia jurídica establece (en términos prescriptivos, en términos de deber ser) los efectos derivados de la materialización de la hipótesis (por ejemplo: el supuesto o hipótesis es el hecho del homicidio; la consecuencia es el deber de permanecer en prisión durante veinte años).

La teoría de la norma de Bobbio supuso una respuesta explícita a la primera cuestión planteada: las normas jurídicas son entidades lingüísticas, son "proposiciones prescriptivas". Pero Bobbio no respondió tan explícitamente a la segunda cuestión: ¿qué clase de entidades lingüísticas son las normas jurídicas? Apuntó que entendía por proposición "un conjunto de palabras que tienen un significado entre sí", una entidad diferenciada del enunciado o "forma gramatical y lingüística con la cual se expresa un significado", de tal forma que una misma proposición puede expre- 
sarse a través de diversos enunciados. Por ejemplo, la proposición prescriptiva "Está prohibido fumar" puede expresarse a través de los enunciados "Está prohibido fumar", "Fumar está prohibido", "Prohibido fumar", "No smoking"....., enunciados con identidad significativa (Bobbio, 1962).

Ciertamente, al definir las normas como "proposiciones prescriptivas" no debe olvidarse que el término "proposición" puede entenderse en sentidos diferentes, que son paralelos a otros tantos diferentes conceptos de "norma".

En realidad, los sentidos del término "proposición" no son sólo dos (como "proposición en sentido estricto" y como "enunciado", de acuerdo con la distinción de Bobbio), sino tres. "Proposición" no sólo puede designar un enunciado y una proposición significativa, sino que también puede designar una "enunciación" concreta de un enunciado (en el idioma inglés, la diferencia entre "enunciado" y "enunciación" de un enunciado parece más clara: "enunciado" es "sentence", "enunciación" de un enunciado es "utterance"). Por ejemplo, el enunciado "Está prohibido fumar" puede "enunciarse" (es decir, de dicho enunciado pueden producirse enunciaciones) en distintos contextos: por una autoridad normativa al prescribir la prohibición de fumar, por un jurista al describir la prohibición de fumar, por un sociólogo al comentar la eficacia de la prohibición de fumar,..... (véase Conte, 1970).

La respuesta negativa a la cuestión de si las normas son entidades lingüísticas la ha dado un reducido sector del sociologismo jurídico. De acuerdo con esta respuesta, la norma es un hecho, pero no un hecho lingüístico (no una enunciación pragmática de un enunciado lingüístico prescriptivo), sino un hecho extralingüístico, una regularidad de comportamiento.
Así, la existencia de la norma sólo significaría que la mayor parte de las personas de un grupo social se comporta de una determinada manera en ciertos tipos de circunstancias. Las normas no serían "fenómenos lingüísticos", sino condiciones sociales fácticas cuya existencia se establece empíricamente (véase Hart, 1961; Ross, 1968).

Quizás quien más claramente concibió la norma como entidad factual y extralingüística fue Theodor Geiger, al distinguir entre la norma (la "norma subsistente") y su expresión lingüística.

Geiger parte de que es consustancial a todo ordenamiento la existencia de un grupo social en el que hay una relación constante entre una serie de situaciones y los correlativos modelos de conducta (Si alguien se halla en la situación S, sigue el modelo de conducta G). Cuando el comportamiento de los miembros del grupo consiste simplemente en "continuar en una regularidad", no existe ninguna relación normativa, ya que el modelo de conducta “carece de 'estigma' u obligatoriedad porque una regularidad fáctica en la secuencia de los sucesos hace inimaginable la disidencia" (Geiger, 1947).

Cuando, por el contrario, el comportamiento de los miembros del grupo no consiste simplemente en "continuar en una regularidad", sino en "seguir una regla", sí existe una relación normativa. Comportarse en desacuerdo con lo que la norma establece no supone entonces sólo "un desvío de la regularidad que de hecho había, sino que es una violación de la normatividad socialmente exigida". La norma existe aunque no exista el enunciado correspondiente, aunque no haya sido "expresado con palabras que ciertas personas están obligadas frente a otras ciertas 
personas a responder a una situación con una cierta conducta". La "norma subsistente" ya "está viva como idea normativa", al margen de que posteriormente pueda o no manifestarse lingüísticamente, de que pueda o no "expresarse y consolidarse en un enunciado normativo que simplemente constata la existencia de una norma subsistente, pero no la crea. Constata que 'Si S, entonces G' es un modelo de conducta habitual, pero no estatuye 'Si S, entonces G' como norma obligatoria". El enunciado prescriptivo es "la simple envoltura lingüística de la norma: expresa la norma, constata su existencia y es por eso puramente declarativo" (Geiger, 1947).

Hart ha destacado que esta concepción de la norma como entidad no lingüística, como mero "comportamiento generalizado", "es la primera explicación de las normas que, quizás naturalmente, nos sentimos inclinados a dar". Pero debe rechazarse porque para que exista una norma no es suficiente la "convergencia de conducta"; es necesario que dicha conducta se "exija", que "tenga que" ("must") darse, que "deba" ("should", "ought to") darse (en este caso Hart identifica la función de "must" con la de "should" y "ought to"): "Todos los miembros de un grupo social pueden beber té regularmente a la hora del desayuno 0 ir al cine una vez por semana, $y$, sin embargo, puede no haber regla que lo "exija'”, puede que el comportamiento no "tenga que" darse, no "deba" darse (Hart, 1961, pp. 9-10).

Si consideramos que las normas son entidades lingüísticas, bien sean enunciados prescriptivos o "deónticos" (situados en un plano sintáctico), proposiciones prescriptivas o "deónticas" (situadas en un plano semántico) o enunciaciones prescriptivas o "deónticas" de enunciados (situadas en un plano pragmático), entonces debemos asimismo considerar que el derecho, como conjunto sistematizado de entidades lingüísticas, es un lenguaje.

Si el derecho es, en sí mismo, un lenguaje, entonces el lenguaje que usa quien habla o escribe sobre el derecho es un lenguaje sobre un lenguaje-objeto, es un metalenguaje. El enunciado "Será nulo el testamento otorgado con violencia, dolo o fraude" (artículo 673 del Código civil español) es un enunciado lingüístico; el enunciado "De acuerdo con el artículo 673 del Código civil español, 'será nulo el testamento otorgado con violencia, dolo o fraude'" es un enunciado transparentemente metalingüístico, un enunciado que versa sobre otro enunciado lingüístico. También sería metalingüístico cualquier otro enunciado, expresado de una u otra forma, que versara sobre el art. 673.

El primer tipo de lenguaje es el lenguaje legal, el lenguaje del texto jurídico con el que el legislador da a conocer las normas jurídicas. Al segundo tipo de lenguaje (que es un metalenguaje, en concreto un lenguaje que versa sobre el lenguaje legal) se le conoce como lenguaje de los juristas, y es el que se utiliza al comentar, analizar o interpretar las normas jurídicas (por ejemplo, lo utiliza el abogado para preparar sus casos y defenderlos en juicio, el juez para motivar su sentencia, el profesor de la facultad de derecho para explicar el derecho vigente). La Ciencia del derecho analiza el derecho como lenguaje, y, respecto al "lenguaje que 'es' el derecho", surge un metalenguaje científico que debe definir las reglas de uso de los términos jurídicos.

En este sentido, Bobbio distinguó tres fases de desarrollo de la Ciencia jurídica (Bobbio, 1962; véase Scarpelli, 1959): 
A) El científico del derecho debe compensar la carencia de rigor del lenguaje legal, debe combatir sus ambigüedades y vaguedades determinando el significado de los términos legales, determinando la "gramática" del lenguaje que emplea el legislador. B) El científico del derecho debe compensar la carencia de plenitud del lenguaje legal, debe "deducir", a través de procesos lógicos de integración, más consecuencias normativas de las que el legislador ha establecido expresamente. C) El científico del derecho debe compensar la carencia de orden del lenguaje legal, debe sistematizarlo progresivamente eliminando incoherencias lingüísticas y teniendo presente el contexto socio-lingüístico de cada momento histórico. Y Felix E. Oppenheim, diferenció dos ámbitos dentro de la Ciencia del derecho: a) desde el punto de vista empírico, la Ciencia del derecho estudia las relaciones entre los "enunciados jurídicos" y las personas que los crean, interpretan y aplican; b) desde el punto de vista lógico, la Ciencia del derecho construye un lenguaje-modelo simplificado correspondiente al conjunto de "enunciados" que expresan un derecho positivo concreto, un derecho positivo determinado espacial y temporalmente (Oppenheim, 1944). Desde este segundo punto de vista, la Ciencia del derecho no estudia empíricamente las relaciones entre las entidades lingüísticas jurídicas y quienes las utilizan, sino las condiciones pragmáticas de validez de dichas entidades. El lenguaje de la lógica está implícito en todo lenguaje jurídico formalizado, y por ello mismo una de las funciones de la Ciencia del derecho debe ser la de formular explícitamente en el lenguaje-modelo los principios jurídicos implícitos (Oppenheim, 1944).

\section{La imperatividad de la norma en cuestión}

A diferencia de la expresión "Lógica Deóntica", el sustantivo "Deóntica", con su significado actual, constituye una destacada aportación de Amedeo G. Conte a la Filosofía del Lenguaje Normativo. Como tal, la Deóntica se enfrenta a los sistemas formales de cálculo deóntico desde el punto de vista de sus fundamentos teórico-filosóficos, reservando a la Lógica Deóntica el análisis de los problemas puramente técnicos propios de dichos cálculos. Retomando a Aristóteles, Conte define la "Deóntica" como "teoría del 'Sollen' en tanto que 'Sollen'”, como "teoría del 'deber ser' en tanto que 'deber ser'”. Así como la Metafísica, como "teoría del 'ser' en tanto que 'ser'", estudia el ser en su "costitutiva onticità", la Deóntica estudia el deber ser en su "costitutiva deonticità"3.

Influida por la tradición imperativista que arranca de Austin, la doctrina dominante presupuso la centralidad de las normas que ordenan o prohíben comportamientos, de lo que Searle y Conte denominarán "reglas regulativas" en oposición a las "reglas constitutivas", concepto que a su vez tiene su origen en la noción wittgensteiniana de regla.

Con el objetivo de racionalizar el ordenamiento jurídico, el proyecto analítico de John Austin de estudio lógico-científico del derecho pasaba por su concepción como "conjunto de mandatos emanados de una autoridad soberana". Austin ampliará y sistematizará el análisis de los conceptos jurídicos realizado por Jeremy Bentham, quien ya había definido el derecho como "conjunto de signos, que expresan una voluntad concebida o adoptada por el soberano en un Estado, 
referentes a la conducta que debe ser observada en un determinado caso por una determinada clase de personas sometidas al poder del soberano".

Austin concibe la norma jurídica como mandato: "las normas jurídicas son mandatos; las normas jurídicas que no son mandatos sólo impropiamente pueden considerarse como tales normas jurídicas". El mandato, que "como idea es la llave para la comprensión de la Ciencia del derecho", es la expresión de un deseo de quien lo enuncia, acompañado de la amenaza de un hipotético "mal" para el caso de que sus destinatarios no lleven a cabo la conducta mandada (Austin, 1885).

La posibilidad del perjuicio, del "mal", determina la vinculación del sujeto pasivo. En palabras de Austin, "es el poder y el propósito de infligir un eventual mal [...] lo que da a la expresión de un deseo el nombre de mandato" (Austin, 1885, p. 91). La conducta mandada puede consistir en hacer o en abstenerse de hacer, por lo que las normas jurídicas se clasifican en preceptivas y prohibitivas: las normas preceptivas imponen el cumplimiento de actos; las normas prohibitivas imponen ciertas omisiones, siempre en conexión con la esfera de acción de otros sujetos.

Desde un punto de vista interno, en el mandato, precisa Austin, coexisten: a) el deseo de un ser racional que otro ser ha de satisfacer mediante una acción o una abstención; b) el hipotético perjuicio, que procederá del primero y recaerá sobre el segundo, si éste no satisface el deseo; c) la expresión del deseo a través de palabras u otros signos lingüísticos (Austin, 1885).

Joseph Raz ha ampliado a seis las condiciones cuyo cumplimiento es necesario para la existencia de un mandato: a) A desea que alguna otra persona se com- porte de cierta manera; b) A expresa este deseo; c) A prevé producir daño al destinatario del deseo si éste no es cumplido; d) A tiene poder suficiente para producir este daño; e) A expresa su intención de producir el daño en ese hipotético caso; f) el mandato expresa el contenido del deseo y de la amenaza de A. En consecuencia, no basta con que el deseo y la amenaza del perjuicio se correspondan con la voluntad de quien manda, sino que tal voluntad ha de hacerse conocer a sus destinatarios, ha de expresarse lingüísticamente (Raz, 1970).

Desde un punto de vista externo, la noción de mandato es correlativa a la de deber y a la de sanción.

En primer lugar, es correlativa a la noción de mandato la de deber. Estar amenazado con un mal para el caso de que incumplamos un mandato equivale, afirma Austin, a estar "atado" u obligado por él, a estar ante el deber de obedecerlo. Mandato y deber se implican recíprocamente: "donde 'reposa' un deber, un mandato 'está significado'; y donde un mandato 'está significado', un deber está impuesto". El mandato se expresa a través del deber que contiene en sí mismo, a través de la referencia a un sujeto pasivo que debe comportarse de determinado modo (Austin, 1885). Tras todo "deber" se esconde un "querer", un acto de voluntad: "B debe hacer $X$ " significa "A quiere que B haga X".

En segundo lugar, es correlativa a la noción de mandato la de sanción. La sanción es "el eventual mal que se padece si se desobedece el mandato, si se incumple el deber de comportarse de acuerdo con el contenido del mandato". Austin se distancia de Bentham al destacar que la sanción, como consecuencia jurídica que enlaza el mandato con su violación, consiste 
siempre en un hipotético perjuicio, nunca en la ausencia de un hipotético beneficio: "las recompensas no se mandan ni obligan", sólo se prometen; una norma jurídica establece deberes, no derechos, por lo que las sanciones consisten siempre en amenazas de males (Austin, 1885).

En todo caso, diversa es la posición sobre las relaciones entre mandato y sanción de imperativistas como Carnelutti, para quien el destinatario de la norma no coincide con el destinatario de la sanción. La sanción es "la determinación de la conducta por personas distintas de los interesados para el caso de que el precepto sea obedecido", de tal manera que si la ley condena al homicida a prisión, no está ordenando al transgresor de la norma, sino a los funcionarios encargados de decidir su pena y ejecutarla (Carnelutti, 1939).

Mandato, deber y sanción se conectan recíprocamente, y se reflejan inseparablemente en la idea austiniana de "la expresión de un deseo unida a la intención de provocar un perjuicio si no es satisfecho". Según se explicite uno u otro aspecto de tal idea, resaltará una de las tres nociones: el mandato hace referencia directa a la expresión del deseo y a su recepción por sus destinatarios, "sin que emerja aún la amenaza del mal"; el deber hace referencia a la posibilidad del perjuicio y sólo indirectamente alude a la expresión del deseo; la sanción hace referencia al mal en sí mismo, sin atender expresamente al deseo y a la amenaza (Austin, 1885).

Para Austin, el término "norma jurídica" sólo impropiamente denota objetos que no son mandatos. Una norma no imperativa no es realmente una norma, sino "un fragmento de otra norma". En concreto, Austin cita los casos de las "normas declarativas" y de las "normas permisivas" (Austin, 1885): a) Las "normas declarativas" son actos del legislador que explican o interpretan normas jurídicas, pero no auténticas normas, salvo si tras la apariencia declarativa se esconde un fondo imperativo. Una norma que define en el Código Civil el término "alimentos" o el término "mayoría de edad" no sería entonces una norma independiente, sino un instrumento de interpretación de otras normas del Código Civil.

b) Las "normas permisivas" son excepciones a la aplicación de normas jurídicas, pero no auténticas normas. No son mandatos sino "revocaciones de mandatos" que liberan de deberes autorizando la realización de acciones u omisiones no permitidas de modo general. Es más, para Austin, refuerzan el carácter imperativo de las normas cuyo ámbito delimitan.

Siguiendo a Austin, ya Del Vecchio indicó que tanto las normas permisivas como las declarativas "son secundarias", no subsisten por sí mismas sino que dependen de normas "primarias" con las que deben ligarse para "descubrir aquello que de jurídico contienen" (Debe aclararse que el sentido de la distinción entre normas primarias y normas secundarias es en Del Vecchio completamente diverso del sentido que le da Hart, al que nos referiremos más adelante). Por ejemplo, el permiso jurídico para no pagar si se ha perdido en un juego ilícito se considera una excepción del mandato general de atenerse a los pactos. Las normas permisivas, recalca Del Vecchio, son "negaciones o derogaciones parciales de imperativos jurídicos" (Del Vecchio, 1965, p. 349).

Austin también se refiere a las normas que confieren derechos y a las normas consuetudinarias, a las que no niega el "carácter propio de leyes", porque, en 
contra de su apariencia, son asimilables a la idea del mandato (Austin, 1885):

a) Una norma que confiere un derecho es un mandato porque impone implícita o explícitamente deberes paralelos, ya que para proteger el ejercicio del derecho carga con deberes a quienes pueden perturbarlo. Por ejemplo, una norma que reconoce un derecho del acreedor sobre el deudor impone simultáneamente al deudor un deber respecto al acreedor.

b) Una norma jurídica consuetudinaria es un mandato porque, a pesar de su supuesta espontaneidad, para considerarse como tal norma jurídica debe haber sido incorporada al ordenamiento por el soberano legislativo a través de sus "delegados judiciales", los Tribunales de Justicia. Antes de la "adopción legal", las costumbres son sólo reglas morales ("rules of positive morality") aunque sean uniformemente seguidas, porque su transgresión no provoca consecuencias jurídicas. Después de la "adopción legal", las normas consuetudinarias son mandatos, ya que han sido indirectamente sancionadas por el soberano mediante la intervención de los Tribunales.

Karl Olivecrona desarrolló un argumento circular para tratar de superar la teoría austiniana de la independencia del soberano frente al ordenamiento jurídico. Para Olivecrona, un Estado no puede existir sin una organización de poder y un conjunto de normas que regula tal organización, sin un ordenamiento jurídico, al que el soberano del Estado debe someterse. Al ordenamiento jurídico no puede precederle ninguna autoridad legislativa ("lawgiving authority"), por lo que las normas jurídicas no pueden concebirse como mandatos o declaraciones de voluntad del soberano (Olivecrona, 1939). Al nivel más alto, una norma fundamental no puede considerarse como el mandato de quien debe su posición a la propia norma fundamental (véase Castignone, 1974).

Ciertamente, la producción legislativa es "autoobligatoria": las normas jurídicas, a diferencia de los mandatos, vinculan también a la "autoridad legislativa", al "soberano legislativo". Es por ello que las tesis imperativistas han sido en ocasiones reinterpretadas identificando al soberano legislativo con el propio Estado o con el propio pueblo. Las normas jurídicas no se concebirían como mandatos procedentes de las personas 99concretas que "encarnan" la autoridad normativa, sino como mandatos procedentes del Estado o del pueblo como entidad soberana abstracta. Olivecrona rechazó asimismo esta ficción por diversos motivos (Olivecrona, 1939):

a) La aparición del Estado es posterior a la aparición del Derecho. Los ordenamientos jurídicos han organizado las comunidades humanas de distintas formas hasta la creación del Estado, que incluso en sí mismo es un producto jurídico. Las normas jurídicas no pueden definirse como mandatos emanados del Estado porque han existido formas jurídicas preestatales.

b) Incluso en el contexto de la realidad jurídico-política contemporánea, considerar al Estado como fuente de todo derecho supone desconocer la existencia de fuentes de producción jurídica como la costumbre, los acuerdos colectivos o el precedente judicial. Las normas jurídicas no pueden definirse como mandatos emanados del Estado porque existen formas jurídicas de procedencia no estatal. 
C) La actuación del Estado, a través de los órganos mediante los que se desarrolla su administración, está también sometida a las normas de procedimiento y competencia establecidas en las normas superiores del ordenamiento. Las normas jurídicas no pueden definirse como mandatos emanados del Estado porque la acción del Estado está precisamente sujeta a las propias normas jurídicas.

Por otra parte, las normas jurídicas tampoco pueden definirse como mandatos abstractamente emanados del pueblo en su conjunto. De acuerdo con Olivecrona, no hay pueblo si antes no hay derecho, ya que sin normas jurídicas no existe cohesión entre los individuos que constituyen el pueblo. El proceso legislativo, en el que en un grado mayor o menor interviene el pueblo, no puede ser independiente de las normas jurídicas que lo regulan. De hecho, si profundizamos en el origen y causa remota de las normas jurídicas, nos perderíamos en la historia. Las normas básicas de los ordenamientos jurídicos surgen hace milenios y han ido paulatinamente modelándose hasta llegar a como son ahora. No pueden identificarse, sin más, con órdenes o mandatos que supuestamente expresan una voluntad anterior al derecho, incluso aunque pensemos en una voluntad abstracta y ahistórica (véase Olivecrona, 1939).

También Ronald Dworkin ha cuestionado el carácter insubordinado e ilimitado del soberano legislativo como supuesta fuente imperativa de las normas jurídicas, lo que asemejaría la relación soberano-súbdito a la relación asaltante-asaltado, ya que ambas se basarían en la amenaza de causar un perjuicio si no se cumple una orden (sea del soberano, sea del asaltante) y en la capacidad fáctica para mate- rializar tal perjuicio. Sólo podemos evitar esta semejanza si concedemos más relevancia al estándard de comportamiento establecido por la norma que a la hipotética sanción. La norma no es obligatoria, recalca Dworkin, por la fuerza de una persona para hacerla cumplir, sino porque se posea autoridad para imponerla, autoridad que sólo puede tener su origen en otra norma (Dworkin, 1977).

En la General Theory of Law and State ("Teoría general del derecho y del Estado", 1945), Kelsen resaltó que las normas jurídicas no pierden su validez por el hecho de que durante su vigencia dejen de corresponderse con la voluntad de quienes en su momento las crearon. La fuerza obligatoria de la norma no se basa en dicha voluntad, sino en lo que tal voluntad crea. La norma entra en vigor cuando la decisión legislativa queda plasmada en el texto legal, y precisamente desde ese momento la voluntad de los legisladores "deja de existir" al respecto, comienza a centrarse en otras cuestiones (Kelsen, 1945). El error de Austin habría consistido entonces en asumir las normas jurídicas como fenómenos psíquicos: "cuando decimos que una cierta conducta se halla 'estipulada', 'establecida' o 'prescrita' por una regla de derecho, empleamos una abstracción que elimina el acto psicológico de voluntad que se expresa en todo mandato". En todo caso, indica Kelsen, la norma jurídica sería "un mandato no psicológico, [...] un mandato que no implica una 'voluntad' en el sentido psicológico del término" porque provoca un "deber" en virtud de la propia norma que no requiere un "querer" paralelo (Kelsen, 1945).

Llama la atención, no obstante, que la obra póstuma de Kelsen Allgemeine Theorie der Normen ("Teoría general de las normas", 1981), suponga una vuelta 
atrás respecto a sus planteamientos antiimperativistas y una aproximación a las ideas del propio Austin. Precisamente uno de los aspectos más radicales de este cambio lo constituye su concepto de norma como sentido de un acto de voluntad: "El acto cuyo sentido es que algo es ordenado, prescrito, es un acto de voluntad. Lo que se ordena, prescribe, es un determinado comportamiento humano [...]. El deber ser, la norma, es el sentido de un querer, de un acto de voluntad y - en tanto que la norma es un precepto, un mandato - es el sentido de un acto dirigido al comportamiento de los demás" (Kelsen, 1981; véase Kelsen, 1965).

Para Olivecrona, los imperativos no tienen necesariamente destinatarios; de hecho, los imperativos sin destinatario son usuales dentro y fuera del lenguaje jurídico. Del mismo modo que el enunciado divino "Hágase la luz" no se dirigió a nadie, no tenía destinatarios, sino que producía efectos por sí mismo, los ordenamientos jurídicos se componen en gran medida de imperativos abstractos, sin destinatarios (Olivecrona, 1939). Cuando un imperativo, aunque expresándose como una orden, tiene como finalidad dar instrucciones sobre la conducta a seguir sin que concurra una relación personal entre quien lo emite y quien lo recibe, estamos ante un "imperativo independiente" de la relación personal, ante un "imperativo impersonal".

Así, las órdenes personales sólo son excepcionales y complementarias respecto a las normas jurídicas, que como tales no mencionan ni se dirigen a personas particulares ni fuerzan a realizar un acto particular. En caso contrario, las normas atraerían la atención de sus destinatarios de la misma forma que un atracador atrae la atención del cajero para que cumpla lo que le ordena (véase Hart, 1961).
Como imperativos independientes o impersonales, las normas jurídicas son el resultado de un conjunto de actos formales. Olivecrona define el "imperantum" como "conjunto de formalidades cuya capacidad para operar sobre la conciencia de ciudadanos y funcionarios se fundamenta en una observancia generalizada". En el marco del "imperantum" se promulgan las leyes y la Constitución, se recogen jurídicamente las costumbres y se planifica el funcionamiento de los órganos parlamentarios y de la Administración pública (Olivecrona, 1939; véase Hierro, 1970).

El acto de promulgación conforme al "imperantum" produce la validez de las normas. La validez normativa no es subjetiva y psicológica, como sugería Austin, sino objetiva e independiente porque, al contrario que el mandato, la norma jurídica es válida al margen de que sea conocida por sus destinatarios y, sobre todo, al margen de que sea temida. Kelsen señaló que existía a este respecto una contradicción en las tesis del propio Austin, porque no se puede hacer depender la obligación de un individuo de su temor a la sanción, y a la vez definir el mandato en base a la posibilidad directa y objetiva de un daño (Kelsen, 1945).

La teoría, expuesta por Kelsen en su "Teoría general del derecho y del Estado", de la norma como juicio hipotético coincide con la teoría de Olivecrona de la norma como imperativo impersonal en abstraer las relaciones entre sujeto activo y sujeto pasivo de la norma, pero se distancia de ella al concebir la norma como mera hipótesis, como mera condición. Con esta teoría, Kelsen pretende superar las críticas del iusnaturalismo al positivismo decimonónico basando sus tesis formalistas e iuspositivistas en puntos de apoyo menos arriesgados que los del imperativismo de 
Austin. Para el primer Kelsen, el derecho es un medio, ya que se compone de normas que establecen hipótesis, supuestos de hecho, que al materializarse provocan la intervención de los jueces; la moral no es un medio, sino un fin en sí mismo que no tipifica las consecuencias del incumplimiento de sus normas. La norma jurídica no es categórica, como la norma moral, sino hipotética, ya que es sólo un nexo entre condiciones y consecuencias. Esta conexión legal entre hecho condicionante y consecuencia origina proposiciones y juicios normativos que no son imperativos: "Imperativa es la expresión inmediata de una voluntad dirigida a provocar una conducta determinada en otro; pero no la expresión de un enlace legal, de una legalidad cualquiera y su correspondiente conocimiento [...]; los hechos, en cuanto tales, bien pueden consistir en imperativos. Pero el derecho, como ley jurídica, es la proposición jurídica, es un juicio hipotético" (Kelsen, 1934, pp. 70-71).

Las leyes naturales también son juicios hipotéticos, siendo la condición la "causa", y siendo la consecuencia el "efecto" ("Si es A, es B": si calentamos el agua a cien grados, hierve; si dejamos caer un objeto, se acelera a $9,81 \mathrm{~m} / \mathrm{s}^{2}$, etc.). La conducta humana es una conducta natural, pero se distingue específicamente de los comportamientos naturales no humanos en la forma en que se relacionan la causa y el efecto, que no se expresa mediante el principio de causalidad, sino que se expresa mediante el principio de imputación: "si se dan determinadas condiciones, deben producirse determinadas consecuencias" " $\mathrm{Si}$ es A, debe ser B": si alguien comete homicidio, debe ser condenado a 20 años de prisión; si alguien arroja un objeto en la vía pública, debe ser condenado al pago de 50000 pts., etc.) (véase Kelsen, 1934).
El deber jurídico no es, como en Austin, consecuencia de la sanción, porque entonces la conducta a realizar no sería la misma que ordena la norma jurídica. Para Kelsen, Austin no es consciente de que la norma no estipula una conducta que considera positiva, sino que parte del comportamiento opuesto, la conducta negativa o antijurídica, a la que imputa una sanción. Al estimar que la norma prescribe la conducta que constituye el deber jurídico, Austin contradice su propia idea de que la norma, como todo mandato, sólo es obligatoria a través de la sanción (véase Kelsen, 1945).

Incluso si se aceptara, en general, la definición austiniana de la norma jurídica como mandato reforzado con la amenaza de un perjuicio, sería difícil aceptar, en particular, la naturaleza imperativa de determinadas clases de normas.

En especial, extender las tesis de Austin al ámbito de las normas dispositivas (de las "reglas hipotético-constitutivas", en expresión de Conte, de las reglas que ponen condiciones de validez de actos jurídicos) significaría concebirlas también como preceptos que ordenan realizar $u$ omitir una acción deseada por el legislador. Si pensamos en supuestos concretos, como en las normas civiles sobre el matrimonio, el testamento o los contratos, no parece nada fácil reconocer como actos de obediencia al legislador los de quienes contraen matrimonio, testan o contratan. Las normas dispositivas no tienen como objetivo prevenir o impedir un perjuicio jurídico, ni ejemplificar con sanciones la obligatoriedad de comportarse de un determinado modo, sino reglamentar facultades que se reconocen a los particulares, poner condiciones de validez de los actos que pueden realizar los particulares en el ejercicio de sus derechos. Son nor- 
mas que no corresponden al esquema formal "Debe ser B", sino al esquema "X debe ser B para contar jurídicamente como Y" (por ejemplo: "X debe ser mayor de edad para contar jurídicamente como contrayente en un matrimonio", "Una declaración de voluntad sobre la disposición futura de bienes propios debe estar firmada para contar jurídicamente como testamento",... etc.).

No obstante, desde la perspectiva imperativista se ha considerado superficial la distinción entre normas imperativas y normas dispositivas, distinción que encubriría una identidad real porque en ambos casos las acciones pueden ser valoradas como jurídicamente correctas o incorrectas. Del mismo modo que la acción "asesinar" es jurídicamente incorrecta conforme a la norma que penaliza el asesinato, la acción "contraer matrimonio siendo menor de edad sin consentimiento de los padres" sería jurídicamente incorrecta conforme a la norma que dispone las condiciones de validez del matrimonio. En este segundo caso, la sanción implícita consistiría en la nulidad del acto jurídico realizado. La existencia de la sanción explicaría que la norma dispositiva también pudiera interpretarse como el mandato de cumplir determinadas condiciones bajo la amenaza de un perjuicio concretado en la nulidad del acto.

Hart ha criticado esta interpretación imperativista cuando ha señalado que "emparejar la nulidad con las sanciones penales equivaldría a concebir las reglas de tanto ('scoring rules') de un juego como dirigidas a eliminar todas las jugadas salvo la conversión de tantos. Si esto tuviera éxito sería el fin de todos los juegos"; sería, análogamente, el fin de instituciones como el matrimonio o la sucesión testamentaria. La nulidad es parte de la nor- ma dispositiva de modo distinto a cómo la sanción lo es de la norma imperativa: "si el hecho de que la pelota no pase entre los postes no significa un 'acto nulo' (la no conversión de un tanto), no se podrá decir que existen reglas de tanteo" (Hart, 1961, 8-9). Distinta de la ilicitud del acto contrario a la norma imperativa es la invalidez del acto contrario a la norma dispositiva. De la misma forma que en el juego del fútbol quien falla un penalti no comete un acto ilícito, no realiza un acto que está prohibido (sólo ocurre que no ha conseguido un gol válido), en Derecho Civil el matrimonio de un menor sin consentimiento o el testamento sin firma no son ilícitos sino inválidos. No es que estén prohibidos, sino que no cuentan jurídicamente como matrimonio ni como testamento (véase Rawls, 1955; Searle, 1969; Azzoni, 1992; Conte, 1992).

\section{Reglas constitutivas: de Kant a Conte}

La tesis imperativista global de Austin choca con la variedad normativa que encontramos en todos los ordenamientos, en los que además de normas que regulan directamente el comportamiento humano encontramos un conjunto de preceptos no destinados a obligar ni a prohibir, sino a organizar, crear instituciones, disponer, etc. Es posible agrupar estas normas con el nombre de reglas constitutivas, de reglas que no regulan formas de conducta sino que las constituyen, por lo que son anteriores e independientes de las respectivas formas de conducta.

En el ámbito de la teoría jurídica contemporánea, se suele considerar a J. Searle como el introductor del término "regla constitutiva" con el significado aludido. Basándose 
en la distinción kantiana entre los principios regulativos y los principios constitutivos, Searle distingue asimismo las regulative rules de las constitutive rules, como reglas que crean por sí misma la posibilidad de jugar un juego (el juego de la familia, el juego de la amistad, el juego de un deporte o, análogamente, el juego del ordenamiento jurídico), como reglas anteriores al propio juego que establecen las posibilidades de actuación en el juego y clarifican el objetivo del juego (Searle, 1969)

No obstante, de modo prácticamente simultáneo a Searle, A. Ross también habló de reglas regulativas y reglas constitutivas. Mientras que las reglas regulativas prescriben cómo tienen que comportarse sus destinatarios, y se refieren a actividades naturales, actividades cuya ejecución es lógicamente independiente de las reglas y anterior a ellas, las reglas constitutivas no prescriben comportamientos y regulan actividades no naturales, actividades que consisten en acciones que deben estar de acuerdo con las reglas y carecen de significado fuera de ese contexto. Las reglas constitutivas "definen la actividad sobre la que versan como institución", afirma Ross, y proporcionan las condiciones lógicamente necesarias para realizar esa actividad como tal institución (Ross, 1971).

Del mismo modo que Ross dividió las actividades en no naturales y naturales, Searle distinguió entre "hechos institucionales" y "hechos brutos", según su existencia presuponga o no la existencia de determinadas instituciones. Sólo por la existencia de una institución tienen valor determinados objetos, actos o situaciones: por ejemplo, sólo en virtud de que existe la institución de la sucesión tiene valor un pedazo de papel firmado por el testador, del mismo modo que a otro nivel sólo en virtud de que existe la institución teórica del lenguaje podemos interpretar las frases escritas en un testamento.

Cada institución es para Searle un sistema de reglas constitutivas, y cada hecho institucional se basa en una o más reglas constitutivas de una institución. En particular, en el contexto de la institución paradigmática de la promesa, debemos aceptar que del simple hecho (aparentemente bruto) de la emisión de determinados sonidos podemos deducir el hecho institucional según el cual se crea una obligación en una persona. Mediante la referencia a la institución de la promesa y, en concreto, a la regla constitutiva "Prometer es asumir una obligación", generamos hechos institucionales, por lo que deducimos un deber ser a partir de un ser.

Junto a MacCormick y Weinberger, Searle es el principal representante del neoinstitucionalismo, de la teoría que define el derecho como hecho institucional, como dimensión de posibilidad de hechos cuya existencia presupone la existencia de instituciones compuestas de reglas constitutivas. El neoinstitucionalismo no concibe el derecho como institución en el sentido de ente o cuerpo social, de organización social, tal como hiciera el institucionalismo de S. Romano, ni tampoco concibe el derecho como institución en el sentido de conjunto de institutos, tal como hiciera el institucionalismo de J. Ray influido por los conceptos savignyanos de instituto jurídico y relación jurídica, sino que concibe el derecho como institución en el sentido de hecho no bruto, de hecho institucional. En particular, en tanto que hecho institucional, el derecho se caracteriza por su socialidad, por su convencionalidad, por su culturalidad y por su simbolicidad.

A partir de la oposición entre los enunciados "constatativos" y los enunciados 
"performativos" (los enunciados que producen determinadas modificaciones de la realidad externa dependientes del contexto institucional en el que se enuncian), Searle define por exclusión los actos "ilocucionarios" como aquéllos en los que, además de pronunciarse determinadas palabras de una forma y en un orden proposicionalmente correctos, se ejecutan acciones que valen o cuentan dependiendo pragmáticamente del contexto institucional. Los hechos son para Searle institucionales en tanto que son regulados por reglas constitutivas, por reglas que siguen el modelo $X$ cuenta como $Y$ o $X$ tiene el valor de $Y$ (a diferencia de las reglas regulativas, que siguen el modelo $\operatorname{Haz} X$ o Si $Y$, haz X). Al redefinir nuevas formas de conducta, las reglas constitutivas recalifican como institucionales hechos que hasta entonces eran brutos.

A diferencia de las reglas regulativas, las reglas constitutivas no pueden ser antinómicas, ni tampoco son susceptibles de incumplimiento. Una regla constitutiva no puede prohibir lo que otra permite ni ordenar lo que otra faculta, ni tampoco puede ser transgredida en sentido estricto. $Y$ del mismo modo que mi movimiento en diagonal de la torre no es inválido, sino que no tiene sentido en el contexto de las reglas constitutivas del ajedrez, la decisión de dos municipios de formar una comunidad autónoma no es tampoco una violación de la Constitución, sino una acción sin sentido en el contexto de las reglas constitutivas que condicionan en el ordenamiento jurídico la creación de Comunidades Autónomas.

En palabras de Conte, las reglas constitutivas pueden definirse ontológicamente en términos de condición. Las reglas constitutivas son condición de concebibilidad, posibilidad y perceptibilidad de la realidad que regulan. Desde un punto de vista semiótico, determinan la intensión o connotación de los términos que se hallan en ellas, con lo que definen la praxis que designan. Y así, en el contexto de la teoría pura del derecho de Kelsen, es posible para Conte considerar la norma fundamental como regla constitutiva del ordenamiento jurídico en tanto que condición lógico-trascendental de pensabilidad de los fenomenos normativos.

Ya en El problema de la Soberanía y la teoría del Derecho internacional, de 1920, Kelsen considera la norma fundamental como idea originaria o hipotética que constituye, produce, su específico objeto de conocimiento, como el presupuesto jurídico fundamental del que se deduce todo el ordenamiento jurídico positivo: "este presupuesto jurídico, este punto de partida, esta norma originaria que llamo constitución en sentido lógico-jurídico - en cuanto que deetermina los órganos supremos del Estado, las fuentes jurídicas supremas - desarrolla plenamente la función de hipótesis fundamental". Esto no significa que todas las normas jurídicas vienen presupuestas materialmente, sino que "la norma originaria hipotética es sólo una suprema regla de produción. El deber jurídico se llena gradualmente de contenido mediante el hecho empírico de las deliberaciones legislativas o las órdenes del monarca, mediante los actos judiciales, mediante las decisiones u ordenanzas de las autoridades administrativas. El contenido de un ser se convierte así en contenido de un deber ser". La norma fundamental "no es puesta ni creada consuetudinariamente, sino que ella misma constituye el presupuesto de la normatividad y la costumbre como fuentes del derecho.

En la primera edición de la Teoría pura del derecho Kelsen insistirá en que una 
pluralidad de normas constituye una unidad, orden o sistema cuando su validez se basa, en último término, en una única norma. Esta norma fundamental "es la fuente común de validez de todas las normas pertenecientes a un mismo orden y constituye su unidad". Sólo la hipótesis de una norma fundamental permite conferir un sentido jurídico a los materiales empíricos, ya que la norma fundamental no es para Kelsen puesta, sino supuesta. Todos los juicios que atribuyen un carácter jurídico a una relación entre individuos "sólo son posibles con la condición general de suponer la validez de una norma fundamental". También en la edición de 1960 de la Teoría pura Kelsen incidirá en la constitutividad de la norma fundamental al resaltar que sólo presuponiendola es posible "interpretar el sentido subjetivo del acto constituyente y de los actos estatuidos conforme a la constitución en sentido objetivo; es decir, como norma jurídica objetivamente válida", de cuya interpretación es la propia norma fundamental condición lógico-trascendental.

Del mismo modo que la distinción kantiana entre los principios regulativos y los principios constitutivos es el precedente de la oposición entre las reglas regulativas y las reglas constitutivas, la noción kantiana de imperativo hipotético ha servido tradicionalmente para explicar la inclusión en los ordenamientos de las reglas técnicas o anankásticas, de normas con una naturaleza diferente de la propia de las reglas regulativas y constitutivas.

En efecto, la oposición entre las reglas técnicas y las normas de conducta está implícita en la distinción de Kant entre la necesidad práctica de los imperativos hipotéticos y la necesidad absoluta de los imperativos categóricos. Los imperativos hipotéticos representan la necesi- dad práctica de una acción posible como medio para alcanzar un determinado fin, bien sea real o potencial. Los imperativos categóricos representan una acción como (absolutamente, objetivamente, categóricamente) necesaria e sí misma, independientemente de su relación con algún fin. En palabras de Kant: "Los imperativos en general ordenan o ho hipotéticamente o categóricamente... Ya que toda ley práctica nos presenta una posible acción como buena, y por ello como necesaria para un sujeto cuya voluntad esté determinada por la razón, todos los imperativos son fórmulas de la determinación de una acción necesaria según el principio de una voluntad en algún aspecto buena. Ahora bien, si la acción se presenta como buena sólo como medio, el imperativo es hipotético, mientras que si queda representada como buena en sí misma el imperativo es categórico", formulable como "actúa sólo según aquella máxima que puedas querer al mismo tiempo que sea una ley universal" ( Kant, 1785, pp. 83 ss.)..

Resulta sin embargo injusto no recordar que ya Aristóteles distinguió en un sentido similar lo hipotético de lo categórico, lo técnico de lo ético, aunque no en referencia a las normas, sino a las virtudes dianoéticas o intelectuales: las virtudes técnicas o "artísticas" y las virtudes éticas o "prudenciales".

Oponiéndolo al conocimiento puramente teórico propio de las ciencias naturales, relativo a leyes de causalidad de cumplimiento necesario, Aristóteles habla de otro tipo de conocimiento, no teórico sino práctico, relativo a todo aquello que puede ser modificado por la acción humana. Dentro de él, diferencia "lo que es objeto de producción" de "lo que es objeto de acción". "Lo que es objeto de producción" hace referencia a la técnica, a lo 
que "versa sobre el llegar a ser, y sobre el idear y considerar cómo puede producirse o llegar a ser algo de lo que es susceptible tanto de ser como de no ser y cuyo principio está en el que lo produce y no en lo producido". La técnica "no tiene que ver ni con las cosas que son o se producen necesariamente, ni con las que son o se producen de una manera natural, porque estas cosas tienen su principio en sí mismas". "Lo que es objeto de acción" hace referencia a la ética, a la "prudencia", "al poder discurrir bien sobre lo que es bueno y conveniente para él mismo, no en un sentido parcial, por ejemplo, para la salud, para la fuerza, sino para vivir bien en general" (Aristóteles, 1982, p. 1140)

Para Kant, como implícitamente para Aristóteles, las reglas técnicas son imperativos hipotéticos; es decir, paradójicamente son reglas a la vez imperativas e hipotéticas. En tanto que imperativa, una regla técnica ordena, expresa un deber ser, es prescriptiva, deóntica (en palabras de Kant, todos los imperativos son expresión del verbo deber, y revelan con ello la relación de una ley objetiva de la razón con una voluntad que, según su constitución subjetiva, no viene necesariamente determinada o coaccionada por ella"). En tanto que hipotética, una regla técnica alude a una hipótesis y de ella hace depender que se esté obligado a realizar una detertminada acción ("el imperativo hipotético dice sólo que la acción es buena para alguna finalidad, posible o real", dice Kant). No hay contradicción porque en las reglas técnicas no se nos ordena "que el fin sea racional y bueno, sino sólo lo que se debe hacer para alcanzarlo".

R. Hare se ha basado en esta aparente paradoja para destacar que los imperativos hipotéticos constituyen la única excepción posible a la ley de Hume, ya que en ellos la gran división entre ser y deber ser desaparece. Un imperativo hipotético es un deber ser; es prescriptivo, deóntico, imperativo. Y deriva de un ser, de la ley física que presupone. El imperativo hipotético "si quieres que hierva el agua, caliéntala a cien grados", que es prescriptivo, deriva de una proposición descriptiva: el agua hierve a los cien grados". Como toda proposición deóntica, un imperativo hipotético contiene para Hare un elemento descriptivo o frástico y un elemento prescriptivo o neústico, que "suele estar escondido en la expresión si quieres", señala Hare. Es decir, se manifiesta pragmáticamente a través del verbo "querer" como un imperativo a pesar de su sintaxis indicativa; expresa pragmáticamente un deber ser, aunque no lo haga sintácticamente (Hare, 1952).

Siguiendo a Hare, también Kalinowski destacó cómo Kant no supo ver que la sintaxis de un enunciado normativo no determina su carácter pragmáticamente hipotético o categórico. Además de asimilar erróneamente "las reglas del obrar dictadas por la prudencia" a las "reglas del hacer", a las reglas (técnicas) "que determinan la acción creadora o productora", y que son siempre hipotéticas y teleológicas en tanto que "obligan sólo en la medida en que el hombre quiere el fin, para cuya realización señalan medios apropiados", Kant no puso de relieve que toda norma puede indistintamente tener una forma lingüística condicional o incondicional independientemente de su verdadero sentido. Una "norma técnica", recalca Kalinowski, puede ser perfectamente expresada a través de una estructura lingüística incondicional: podemos decir con una sintaxis condicional que "si alguien quiere dilatar un metal debe aumentar convenientemente la tempera- 
tura", pero también con una sintaxis incondicional que "quien quiera dilatar un metal debe aumentar convenientemente la temperatura", sin que se altere el significado de la regla técnica. Recíprocamente, una "norma moral" puede expresarse a través de una estructura lingüística condicional, bien sea por su generalidad, bien sea para destacar sus condiciones de aplicación, bien sea para precisar su fundamento. En el primer caso podemos decir con una sintaxis incondicional que "todo contribuyente debe hacer en tiempo oportuno su declaración de impuestos", y, con el mismo significado, por su generalidad, podemos decir con una sintaxis condicional que "si alguien es contribuyente, entonces debe hacer en tiempo oportuno su declaración de impuestos". En el segundo caso podemos decir con una sintaxis incondicional que "la escritura de venta de un bien inmueble debe ser redactada ante un notario", y, con el mismo significado, para destacar sus condiciones de aplicación, podemos decir con una sintaxis condicional que "si el objeto de la venta es un bien inmueble, entonces la escritura de venta debe ser redactada ante un notario". Y en el tercer caso podemos decir con una sintaxis incondicional que "Juan debe decir la verdad", y, con el mismo significado, haciendo explícita la razón de su fuerza obligatoria, podemos decir con una sintaxis condicional que "si Juan es libre y consciente, entonces debe decir la verdad (Kalinowski, 1967).

En todo caso, Kalinowski no cuestionó la imperatividad o deonticidad de las "normas técnicas", de los imperativos hipotéticos, que entrañan para él "obligaciones normativas", aunque de diferente naturaleza que las obligaciones propias de las "normas morales", de los imperativos categóricos. Kalinowski defiende la llamativa tesis de la apofanticidad normativa (las normas son verdaderas o falsas; en particular son verdaderas si derivan del derecho natural), y no la trata de aplicar sólo a los imperativos categóricos, de los que se desprenden "obligaciones morales", sino también a los imperativos hipotéticos. La "proposición anankástica" en la que se basa una regla técnica, en tanto que constata la relación entre un hecho o un estado de cosas "dependiente de una acción consciente y libre", y otro hecho o estado de cosas "susceptible de ser deseado por el eventual autor de la acción", crea una relación normativa deóntica que conecta al agente que desea el segundo hecho o estado de cosas con la acción que produce el primero. Esta relación es una relación de "necesidad deóntica" específica, una relación que no consiste en una obligación moral, recalca Kalinowski, pero que sí es obligatoria en tanto que establece como necesario realizar la acción en cuestión (Kalinowski, 1967, pp. 320 ss.).

Dentro de los imperativos hipotéticos, Kant diferencia los imperativos "pragmáticos" de las reglas puramente técnicas. Los primeros representan "la necesidad práctica de una acción como medio para promover la felicidad"; no son necesarios para una finalidad incierta, simplemente posible, sino para "una finalidad que se puede presuponer con certeza y a priori en todo hombre porque pertenece a su esencia". Por su parte, el imperativo que se refiere "a la elección de medios para la felicidad propia es siempre meramente hipotético, ya que la acción no es ordenada absolutamente, sino sólo como medio para una finalidad diferente" (Kant, 1785, pp. 84 ss.). Para Bobbio, un imperativo pragmático kantiano sería: "si quieres ser feliz, debes evitar todo exceso"; el fin es real porque depende de una necesidad 
natural como la de ser feliz "que se puede decir que todos los hombres tienen efectivamente". Un imperativo técnico kantiano sería: "si quieres aprender latín, debes hacer muchos ejercicios prácticos"; el fin es sólo posible porque" es indiferente alcanzarlo o no alcanzarlo, y en ambos casos lícito (Bobbio, 1962, pp. 107-108).

Mediante esta subdivisión, Kant acaba por distinguir en realidad tres tipos de imperativos diferentes: los imperativos categóricos o morales, relativos "al comportamiento libre en general, a las costumbres", los imperativos (hipotéticos) pragmáticos, "relativos al bienestar", y los imperativos (hipotéticos) técnicos, "relativos al arte". Los imperativos categóricos son "mandatos o leyes de la moralidad", los únicos que conllevan una "necesidad incondicional, objetiva, y por tanto universalmente válida". Los imperativos pragmáticos son "consejos de la prudencia", que contienen "una necesidad condicionada de forma subjetivamente accidental al sentido de la felicidad de cada persona". Los imperativos técnicos son simples "reglas de habilidad": "la cuestión del modo en que sea posible un imperativo de la habilidad no exige en realidad particulares explicaciones: quien quiere el fin quiere también (en la medida en que la razón tenga una influencia decisiva sobre sus acciones) el medio necesario para alcanzarlo cuando esté dentro de sus posibilidades" (Kant, 1785, pp. 86).

Bobbio ha puesto de manifiesto que la figura del derecho subjetivo ha resultado ser incompatible para parte de la doctrina con las normas éticas, las cuales imponen categóricamente acciones como buenas en sí mismas e implican obligaciones, no facultades jurídicamente protegidas. El ordenamiento jurídico aparece así globalmente como un instrumento para alcan- zar el fin de la paz social que se compone de reglas técnicas, de reglas que sin embargo expresan auténticos deberes jurídicos. Pero entonces no sería fácil diferenciar las reglas jurídicas de las reglas de los juegos, que también pertenecen a ordenamientos normativos innstrumentales. Bobbio por el contrario recurre a la distinción kantiana entre los imperativos hipotéticos "pragmáticos" o reglas instrumentales con un fin real, como las normas jurídicas, y los imperativos hipotéticos "técnicos" o reglas instrumentales con un fin posible, como las reglas de los juegos. A diferencia del fin del reglamento de un juego, el fin del derecho es un fin al cual no podemos renunciar porque "todos estamos obligados a jugar al juego del derecho". No cabría entonces decir que "si quieres vivir en sociedad, debes someterte a la vida en común comportándote tal como las normas jurídicas prescriben", sino, incondicionalmente, que "como debes vivir en sociedad, debes someterte a la vida en común comportándote tal como las normas jurídicas prescriben" (Bobbio, 1962, pp. 139 ss.).

Ello no implica para Bobbio poner en cuestión el carácter hipotético de las normas jurídicas, frente al carácter categórico de las normas morales. La voluntad jurídica se diferencia de la voluntad moral en que puede tener motivos distintos del puro respeto al orden del que emana, y en tanto que libertad externa viene determinada por la coacción que pueden ejercer los titulares de las restantes libertades externas, por lo que es una voluntad heterónoma. Y, basándose en Kant, Bobbio argumenta que la heteronomía de las normas jurídicas implica su hipoteticidad. Si una voluntad se determina por un objeto externo, y es por tanto heterónoma, "es signo de que el imperativo no ha 
prescrito una acción buena en sí misma", como hacen los imperativos categóricos morales, sino una acción cuyo cumplimiento se hace depender "de la voluntad de alcanzar el objeto externo al propio deseo". El deber jurídico consiste así en la facultad externa de obligar a cumplir las normas jurídicas, que no se formulan categóricamente ("Debes hacer X"), sino hipotéticamente ("Si quieres evitar una consecuencia jurídica desfavorable, debes hacer X").

En la Deóntica contiana, las reglas constitutivas se definen como el "'prius' de aquello sobre lo que versan en el triple sentido de que de ello son condición (eidética) de concebibilidad, condición (alética) de posibilidad y condición (noética) de perceptibilidad". Las reglas constitutivas no versan sobre actos, situaciones 0 entidades cronológicamente preexistentes ni ontológicamente independientes, sino que en sí mismas constituyen la actividad sobre la que versan y, en ella, su praxis. La distinción entre "constitutividad categórica" y "constitutividad hipotética" es paralela a la distinción entre las nociones de "regla constitutiva" y "regla hipotético-constitutiva", distinción que Conte expresa en términos ontológicos y en términos semióticos:

a) En términos ontológicos, las reglas constitutivas son condición de las actividades sobre las que versan: " $X$ cuenta como $Y$ ", " $X$ tiene el valor de Y"; las reglas hipotético-constitutivas ponen condiciones para que un acto o circunstancia posea un determinado valor: " $X$ debe ser $N$ para contar como $Y$ ", "X debe ser $N$ para tener el valor de Y" (En tercer lugar, las reglas técnicas no son condición, ni ponen condiciones, sino que presuponen condiciones: prescriben comportamientos bajo la condición subjetiva de perseguir un fin y en tanto que condición objetiva de consecución del fin que se persigue).

b) Desde el punto de vista semiótico, las reglas constitutivas determinan la connotación de los términos que designan la praxis constituida por ellas. Las reglas hipotético-constitutivas no determinan, sino que presuponen la connotación de los términos que designan la praxis coonstituida por ellas; es decir, establecen su denotación al poner condiciones de validez de las entidades designadas por estos términos.

Las reglas hipotético-constitutivas, también denominadas reglas anankásticoconstitutivas, ejemplifican lo que Conte denomina el "Deon" anankástico, contrapuesto al "Deon" deóntico ("Deon", participio neutro del verbo impersonal griego "Dê̂", es, sustantivado, el término que Aristóteles empleó para referirse a la necesidad normativa). Esta contraposición es básica en Deóntica porque profundiza, a juicio de Conte, en una cuestión crucial en relación con el fundamento de la Lógica Deóntica: la diferenciación entre la necesidad "no-normativa" (y los conceptos modales no-normativos de posibilidad, imposibilidad y contingencia) y la necesidad "normativa" (y los conceptos modales normativos de permisión, prohibición e indiferencia): El "Deon" anankástico es un ejemplo de necesidad normativa no deóntica, de "Deon" adeóntico. La relevancia de la distinción entre "Deon" deóntico y "Deon" (adeóntico) anankástico se pone de manifiesto por el hecho de que, como recalca Conte, la indiferencia deóntica no posee correspondencia anankástica, ya que la indiferencia anankástica es autocontradictoria. Es más, del mismo modo que la mera existencia de una teoría for- 
mal relativa a entidades anapofánticas demuestra que la lógica va más allá del lenguaje apofántico, la mera posibilidad de una teoría formal relativa a reglas adeónticas (por ejemplo, reglas anankásticoconstitutivas) demuestra que la deóntica va más allá del lenguaje deóntico (Conte, 1992).

\section{La tipología del concepto de validez}

En su trabajo "Minima deontica" (1988), Conte construyó el "triángulo deóntico de la validez", cuyos tres vértices representaban la validez deóntica sintáctica, la validez deóntica semántica y la validez deóntica pragmática. En cierta forma, respondía así a la pregunta que él mismo formuló dieciocho años antes en "Studio per una teoria della validità": "¿De qué cosa se predica la validez que es precisamente el objeto de la teoría de la validez?" Entonces, Conte se limitó a elaborar una tetracotomía del término "norma" paralela a la distinción, propia de la teoría de los actos lingüísticos, entre cuatro sentidos del término "proposición": entendido como "sentence" ("enunciato linguistico", "Satz"), entendido como "utterance" ("enunciazione d'un enunciato", "Äusserung"), entendido como "proposition" en sentido estricto ("ciò che un enunciato esprime,... proposizione 'strictu sensu'") y entendido como estado de cosas sobre el que el enunciado versa. La tetracotomía de "norma" era la siguiente:

a) "norma" como enunciado deóntico ("el comportamiento C es obligatorio", "el comportamiento C está prohibido", "el comportamiento C está permitido").

b) "norma" como acto de enunciación deóntica de un enunciado deóntico. c) "norma" como proposición deóntica expresada por un enunciado deóntico.

d) "norma" como status deóntico, como hecho extralingüístico sobre el que versa el enunciado deóntico (una obligación, una prohibición, un permiso).

En "Minima deontica", Conte desarrolla esta delimitación conceptual respecto al problema de la validez.

La validez sintáctica, predicable de status deónticos, es la validez "relativa a reglas constitutivas sobre la validez, a las reglas constitutivas de un ordenamiento que (condicionando la validez de status deónticos en el ordenamiento y por el ordenamiento) determinan la sintaxis de validez de dicho ordenamiento". Por consiguiente, la validez sintáctica es relativa: a) a un ordenamiento (ya que es validez en y por un ordenamiento; b) dentro del ordenamiento, "a la regla noético-constitutiva llamada Norma Fundamental (Grundnorm)".

La validez semántica, predicable de enunciados deónticos, depende de la correspondencia de un enunciado deóntico con un status deóntico. La validez sintáctica de un status deóntico es condición suficiente de validez semántica del enunciado deóntico correspondiente. El enunciado deóntico "Está prohibido fumar en la universidad" es semánticamente válido si es verdad que está prohibido fumar en la universidad; es decir, si es sintácticamente válido el status deóntico "Está prohibido fumar en la universidad".

Los conceptos de "validez semántica thética" y "validez semántica athética" reproducen la polémica teórica entre iuspositivismo e iusnaturalismo: La validez semántica thética de un enunciado deóntico depende de su correspondencia con un status deóntico (théticamente) constituido en un ordenamiento y por un orde- 
namiento; la validez semántica athética de un enunciado deóntico depende de su correspondencia, en palabras de Kalinowski, con la "realidad deóntica".

No obstante, la expresión "validez semántica" es, en Conte, posterior al concepto de "validez semántica". En "In margine all'ultimo Kelsen" Conte se refirió ya a la aplicabilidad de los principios lógicos a la validez de las "proposiciones prescriptivas" entendida como verdad (utilizando la expresión posterior, a la validez semántica de las normas como enunciados deónticos) partiendo de la siguiente hipótesis: "Las proposiciones prescriptivas pueden ser o verdaderas, o falsas, ya que son o verdaderas, o falsas (ab esse ad posse valet consequentia); son o verdaderas, o falsas, ya que son verdaderas (una disyunción es verdadera si es verdadero uno de sus términos); son verdaderas porque son necesariamente verdaderas".

Diez años después, en "Aspetti della semantica del linguaggio deontico", Conte rechazó la incompatibilidad entre verdad y performatividad de un enunciado deóntico. Que la enunciación performativa de un enunciado no sea ni verdadera ni falsa, sino válida o inválida, no significa que el enunciado que se enuncia performativamente no pueda ser verdadero ni falso. Por contra, un enunciado performativo es verdadero precisamente en tanto que se usa performativamente, en tanto que quien lo enuncia, al enunciarlo performativamente, hace lo que dice: "la performatividad de la enunciación es condición necesaria y suficiente de verdad del enunciado".

La validez pragmática, predicable de actos deónticos, o bien depende de las condiciones de validez (théticamente) puestas en un ordenamiento por reglas hipotético-constitutivas (validez pragmática "thética" o "praxeonómica"), o bien depende de las condiciones (athéticas) inherentes al concepto de los actos deónticos, a su intrínseca constitución (validez pragmática "athética" o "praxeológica") .

Para Conte, la validez pragmática de un acto deóntico es condición suficiente pero no necesaria de validez sintáctica del status deóntico producido. Explícitamente señala Conte que "la validez pragmática (en y por un ordenamiento S) de la enunciación thética de un enunciado deóntico es condición suficiente de validez sintáctica (en y por un ordenamiento S) del status deóntico del cual el acto deóntico es thésis. La validez sintáctica (en y por S) del status deóntico es, a su vez, condición suficiente de validez semántica (en y por S) del enunciado deóntico".

Un enunciado deóntico es prgmáticamente ambivalente porque es susceptible de enunciaciones hetereogéneas: se enuncia deónticamente si es un enunciado deóntico prescriptivo (si es un enunciado deóntico "in suppositione deontica"), o se enuncia adeónticamente si es un enunciado deóntico descriptivo (si es un enunciado deóntico "in suppositione adeontica") ${ }^{19}$. Ejemplos clásicos de enunciados deónticos "in suppositione adeontica" son, para Conte, los "Sollsätze" kelsenianos, los enunciados apofánticos sobre el "Sollen".

Conte aclara que su tesis de la ambivalencia pragmática de los enunciados deónticos (enunciación deóntica de un enunciado deóntico vs. enunciación adeóntica de un enunciado deóntico) no implica la tesis de la ambigüedad semántica (según se enuncie por un legislador o por un sociólogo) de enunciados adeónticos de la forma "La acción A se castiga con la sanción 
S". Tanto el legislador como el sociólogo pueden enunciar, por ejemplo, el enunciado "El homicidio se castiga con veinte años de prisión" sin que en ninguno de los dos casos el enunciado sea semánticamente ambiguo. En el primer caso, el legislador constituye una regla, asume como thésis la relación entre el homicidio y la pena de veinte años de prisión prescribiendo dicha sanción para dicho acto. En el segundo caso, el sociólogo constata una regularidad, analiza la relación entre la norma que castiga con veinte años el homicidio y la realidad social describiendo una situación.

Distinta de la tesis de la ambivalencia pragmática de los enunciados deónticos (enunciación deóntica de un enunciado deóntico vs. enunciación adeóntica de un enunciado deóntico) es la tesis de la adeonticidad de los enunciados descriptivos de la forma "La norma 'El homicidio se castiga con veinte años de prisión' es (deónticamente) válida". Del carácter adeóntico de enunciados como el citado, Conte extrae una importante conclusión: si la Lógica Deóntica se concibe como lógica de enunciados deónticos, no puede ser una lógica de enunciados descriptivos adeónticos sobre la validez (deóntica).

Respecto a las relaciones entre lo deóntico y lo adeóntico existe un triple riesgo de falacia naturalista. En palabras de Conte, es posible una falacia naturalista "noética" relativa a conceptos, una falacia naturalista "dianoética" relativa a enunciados, y una falacia naturalista axiológica relativa a la verdad de enunciados:

a) Constituye una falacia naturalista "noética" definir un concepto deóntico mediante conceptos adeónticos.

b) Constituye una falacia naturalista "dianoética" derivar un enunciado deónti- co de enunciados adeónticos. El hecho de que una norma sea dianoética o inferencialmente válida no implica que tal norma sea deónticamente válida en el ordenamiento en el que son deónticamente válidas las normas de las que deriva, las normas respecto a las cuales es dianoéticamente válida. La validez deóntica de una norma no es relativa a las normas de las que depende su validez dianoética, sino a las reglas constitutivas que, en y por un ordenamiento, condicionan tal validez deóntica.

c) Constituye una falacia naturalista axiológica derivar la verdad deóntica de un enunciado deóntico de su verdad adeóntica. Refiriéndose a las contradicciones divisionistas sobre el rechazo de una "ought-sentence" incompatible con una ley transcultural supuestamente necesaria, Conte ya negó, desde sus primeros escritos, la inexistencia absoluta de relaciones lógicas entre "is-sentences" y "oughtsentences", sin que ello significara rebatir los argumentos divisionistas, sino reformularlos en términos lingüísticos (no como división entre dos mundos, el mundo del "is" y el mundo del "ought", sino como división entre dos modos del lenguaje: la verdad (la verdad deóntica) de "ought-sentences" y la validez (la verdad adeóntica) de "ought-sentences").

En esta misma línea, la concepción del fenómeno de la derogación desde una perspectiva no estrictamente normativista es explicada por Conte basándose en las tesis de Alchourrón y Bulygin, "Sobre la existencia de las normas jurídicas": Enunciados de la forma "La norma n es derogada", al enunciarse performativamente, no son normas, son "expresiones verbales 
de actos de rechazo", son "actos théticos de invalidación de status deónticos".

A diferencia de los verbos performativos que Conte denomina "rhéticos", que significan la ejecución de un acto lingüístico que como tal no actúa sobre la verdad del enunciado (es decir, de un acto lingüístico "rhético", de un acto que es una "rhesis"; por ejemplo, comunicar, comentar, replicar,...), los verbos performativos théticos significan una posición de verdad, una "thésis", mediante un acto lingüístico, de la verdad de un enunciado. "Derogar" es un verbo thético "factitivo": significa la posición de no verdad, en una convención y por una convención, de un enunciado presupuesto verdadero.

La validez deóntica que suprime un acto derogatorio es validez sintáctica. Como indica Conte, "obiectum affectum" de la derogación es la validez sintáctica de un status deóntico en un ordenamiento; "obiectum effectum" de la derogación es su invalidez sintáctica. La validez deóntica que se predica de un acto derogatorio es validez pragmática "thética" o "praxeonómica", validez condicionada por las reglas hipotético-constitutivas que (théticamente) ponen las condiciones de validez de un acto derogatorio en un ordenamiento y por un ordenamiento.

En tanto que produce una transición de la validez sintáctica de un status deóntico a su invalidez sintáctica, todo acto derogatorio posee, siguiendo a Conte, una "diacronicità costitutiva". Así, el fenómeno diacrónico de la derogación exige, respecto a la teoría general del ordenamiento, la superación del modelo kelseniano tridimensional. Exige para los sistemas normativos dinámicos un modelo tetradimensional, un modelo espacio-temporal.

\section{Juegos del lenquaje, forma de vida y argumentación jurídica}

En repetidas ocasiones, Perelman ha señalado que las teorías de la argumentación no deben ser lógicas, sino psicológicas. Los razonamientos jurídicos han de ser retóricos, no analíticos ni lógico-formales, y tener como destinatario el auditorio universal o conjunto ideal de individuos a los que el acto discursivo influye perlocucionariamente. A diferencia de la mera demostración lógica, que es independiente de los efectos perlocucionarios, la argumentación retórica requiere la aceptación por parte del auditorio, por lo que quien argumenta no es libre al elegir los argumentos (como el lógico lo es al escoger sus axiomas siempre que respete criterios formales, y en particular el principio de no contradicción) y debe cumplir una serie de condiciones materiales de las que depende la validez de su discurso. No basta con persuadir a un auditorio particular, recalca Perelman, sino que es necesario convencer al auditorio universal para así conseguir que el argumento utilizado sea no sólo eficaz, sino también válido.

Las tres principales técnicas argumentativas son para Perelman los argumentos cuasi-lógicos, los argumentos basados en la estructura de lo real y los enlaces que fundamentan la estructura de lo real. En los primeros hay un esquema formal que sirve de modelo del argumento y unas operaciones de reducción que permiten introducir los datos en el esquema y homogeneizarlos. Perelman aclara que el empleo de esta técnica no significa priorizar el razonamiento puramente lógico sobre el argumentativo, ya que el primero resulta de un proceso de simplificación 
que exige unas condiciones muy concretas y su aplicación en el interior de sistemas aislados. Argumentos cuasi-lógicos son la contradicción, la identidad total, la identidad parcial y la transitividad (todos ellos basados en estructuras lógicas), y por otro lado la relación de la parte con el todo, la relación entre partes de un todo, los argumentos de comparación y los argumentos de frecuencia (basados en relaciones matemáticas). Los argumentos basados en la estructura de lo real, a diferencia de los argumentos cuasi-lógicos, no se apoyan en la racionalidad derivada de su deductividad lógica o matemática para justificar su validez, sino que se basan en tal validez para, en palabras de Perelman, "establecer una solidaridad entre juicios admitidos y otros que se intenta promover". Puedan o no justificarse, garantizan de hecho el desarrollo de la argumentación. Dentro de ellos, Perelman distingue los enlaces de sucesión (el nexo causal, el argumento pragmático, la relación de un hecho con su consecuencia o de un medio con su fin, el argumento del despilfarro, el argumento de la dirección y el argumento de la superación ) y los enlaces de coexistencia, que no unen como en la sucesión dos términos en conflicto situados en un mismo plano, sino dos realidades de las que una es más explicativa y fundamental y está mejor estructurada. Finalmente, los enlaces que fundamentan la estructura de lo real son el fundamento por el caso particular y, sobre todo, el razonamiento por analogía, que para Perelman es desde el utilitarismo el eslabón más débil de la serie identidad-semejanza-analogía. El razonamiento por analogía en sentido estricto se identifica a su juicio con el comparativismo jurídico, ya que consiste en la comparación respecto a una determinada materia del tratamiento que recibe en ordenamientos jurídicos de países diferentes y de épocas diferentes, y en sentido más amplio se define como similitud de estructuras, formalizable como $A / B=C / D$ : $A$ es a $B$ (tema) como $C$ es a $D$ (foro). Lo esencial en la analogía es confrontar el tema con el foro, aunque ello no presupone una relación previa entre los términos de ambos. A diferencia de lo que ocurre con la proporción matemática, la naturaleza de los términos nunca es indiferente en la analogía, y marca las relaciones entre tema y foro, que se manifiestan mediante la estructuración y transferencias valorativas recíproca (Perelman, 1989, pp. 313 ss.).

En síntesis, en Perelman es, como en Viehweg, patente la oposición entre la argumentación dialéctica y la demostración lógica, entre la sumisión a las condiciones de construcción de un discurso racional y la libertad procedimental de escoger cualquiera de los axiomas lógicos, respectivamente. Y frente a la tópica y a la retórica, Robert Alexy ha proclamado la naturaleza analítico-normativa de su teoría de la argumentación jurídica concibiendo el discurso práctico como actividad guiada por reglas constitutivas, y utilizando la nueva pragmática lingüística originada a partir de los conceptos wittgensteinianos de juego del lenguaje y seguir una regla, y consolidada con la teoría de los actos del habla de Austin y la lógica del lenguaje moral de Hare, e incluso con la teoría de la argumentación moral de Toulmin, basada asimismo en la idea de que el lenguaje es una herramienta que se puede usar para fines no descriptivos, y en los que por tanto no tendría por qué primar el criterio de la verdad como correspondencia. Al enjuiciar las teorías emotivistas, Alexy destaca que han servido para dejar claro que la función del lenguaje moral va más allá de su uso descriptivo, pero rechaza el emotivis- 
mo porque prescinde de la idea de que el discurso práctico es una actividad guiada por reglas, lo que le acerca asimismo al concepto wittgensteiniano de "seguir una regla", desarrollado por Searle y Conte. Seguir u obedecer una regla es también para Wittgenstein y para Conte una práctica, un uso, una costumbre, un acto institucional, por lo que no cabe un cumplimiento privado o interior. El concepto de seguir una regla, unido a los conceptos de juego del lenguaje y forma de vida, sirve a Alexy para fundamentar los presupuestos del discurso práctico racional.

En tanto que teoría (además de analítica) normativa, la teoría del discurso racional plantea como primer problema la fundamentación de sus reglas sin incurrir en el regreso al infinito (las reglas se justifican mediante metareglas de segundo nivel, que se justifican mediante metareglas de tercer nivel, y así sucesivamente). Alexy distingue cuatro posibles tipos de fundamentaciones: 1)Una fundamentación técnica, que consistiría en considerar las reglas del discurso como reglas que establecen los instrumentos para la consecución de determinados fines; 2) Una fundamentación empírica, que consistiría en mostrar las reglas que de hecho se siguen; 3) Una fundamentación definitoria, que consistiría en analizar las reglas que crean, constituyen o definen la praxis institucional; 4) Una fundamentación pragmático-universal, que consistiría en tomar la validez de determinadas reglas como condición de posibilidad de la comunicación lingüística. Alexy parece inclinarse levemente a favor de este último tipo de fundamentación, llevado a cabo por Apel y Habermas, así como, en una variante débil, por Austin y Searle con sus teorías de los actos lingüísticos. Sin embargo, eclécticamente, hace hincapié en los aspectos positivos de cada una de ellas, lo que le lleva a conceptuar su posición al respecto como "discurso teóricodiscursivo".

Así pues, la argumentación jurídica es regida en buena medida para Alexy por las reglas generales de la argumentación práctica, que divide en seis tipos: las "reglas fundamentales" ("Ningún hablante puede contradecirse", "Todo hablante sólo puede afirmar aquello que él mismo cree", "Todo hablante que aplique un predicado determinado a un objeto determinado debe estar dispuesto a aplicarlo a cualquier otro objeto que tenga los mismos aspectos relevantes", "Distintos hablantes no pueden usar la misma expresión con distintos significados"), las "reglas de razón" (que derivan de la regla "Todo hablante debe, cuando se le pide, fundamentar lo que afirma, a no ser que pueda dar razones que justifiquen el rechazar una fundamentación"), las reglas sobre la carga de la argumentación (que derivan de la citada regla de razón y del principio de universabilidad de Hare, en conexión con el principio de inercia de Perelman), las reglas que Alexy denomina formas de argumento, las reglas de fundamentación (presididas por el principio de generalizabilidad en una reconstrucción ecléctica de las versiones de Hare, Habermas y Bauer) y las reglas de transición, que se pueden emplear para pasar de la argumentación práctica a un discurso teórico, a un discurso de análisis lingüístico o a un metadiscurso.

Alexy asume la argumentación jurídica como actividad lingüística que se refiere al discurso jurídico como caso especial del discurso práctico general, del discurso referido a las cuestiones prácticas (deónticas) sobre lo que se debe hacer o se debe no hacer. Esto no significa que el discurso 
jurídico atienda exclusivamente a cuestiones prácticas, sino que también se ocupa de problemas empíricos, de hechos, por lo que la teoría de la argumentación jurídica deberá servirse de otras disciplinas como la sociología jurídica, la teoría del derecho, la historia del derecho,...; tampoco significa que la argumentación jurídica haya de atender estrictamente a la racionalidad abstracta de la decisión jurídica, sino a su fundamentación racional en el contexto del ordenamiento jurídico positivo; y, por último, tampoco significa que a través de la argumentación jurídica se persiga el consenso absoluto respecto a cada decisión jurídica, sino que se acepten al menos una serie de presupuestos comunes (Alexy, 1989, pp. 178 ss.).

La fundamentación racional de las decisiones jurídicas exige en primer lugar para Alexy su justificación interna, es decir, su corrección lógica, su validez inferencial, lo que nos sitúa ante la cuestión centralmente contiana de la posibilidad de construir silogismos jurídicos, cadenas lógicodeductivas que a partir de una premisa mayor normativa universal y una premisa menor fáctica particular deriven una conclusión normativa particular.

Los conceptos wittgensteinianos de "juego del lenguaje" y "forma de vida", prolongados articuladamente por Conte, son decisivos para explicar el trasfondo de la teoría de la argumentación jurídica como tipo específico de discurso práctico, basada en estos tres principios: a) El uso descriptivo del lenguaje es sólo uno más dentro de las infinitas posibilidades lingüísticas de las que disponemos, entre las que destaca el lenguaje normativo, el cual ni tiene por qué reducirse al descriptivo ni es menos relevante que él; b) Para comprender la lógica de los juegos de lenguaje se debe considerar el comportamiento no verbal y otras circunstancias fácticas: c) Al igual que los juegos lingüísticos, los discursos morales y jurídicos son actividades guiadas por reglas. En su reconstrución de la racionalidad como razonabilidad (The $R a$ tional as Reasonable, 1987), Aulis Aarnio ha desarrollado también esta línea teórica al servirse del concepto de forma de vida para explicar su tesis de que, en la praxis societaria, los sistemas de valores no son creados autónomamente por individuos o grupos: "cada enunciado valorativo se conecta con una totalidad compleja de enunciados. Siguiendo a Ludwig Wittgenstein se podría hablar de un nido de enunciados. Este nido de enunciados no es, sin embargo, arbitrario, sino que como globalidad se liga a una base, a una forma de vida". Aarnio recalca que los sistemas de valores están "vinculados a nuestra práctica vital", sin que por ello deje de ser posible justificar una teoría de los valores no-descriptiva, que como tal tampoco deja de ser una teoría racional. Cuando se expresa un juicio de valor, señala Aarnio, se está jugando un determinado juego lingüístico. Quien dice que A es bueno o es malo realiza una opción ética que no es meramente teórica, sino que consiste en una acción que no se puede justificar más que situándola en el contexto de una forma de vida, la cual no es en sí misma susceptible de justificación.

Ciertamente, el segundo Wittgenstein modifica su idea del Tractatus de que el mundo y el lenguaje poseen una estructura común a través del concepto de juego lingüístico. Ahora reconoce que las reglas que regulan las constantes lógicas no se pueden establecer al margen de la relación interna de las proposiciones en las inferencias lógicas, porque estas reglas, esta sintaxis, forma parte de una sintaxis global mediante la cual se puede analizar 
la función que cumplen tales relaciones internas. La sintaxis o gramática de nuestro lenguaje ofrece reglas que establecen la relación interna entre un término y su significado, y a partir de las cuales se pueden expresar enunciados sintéticos a priori (en el lenguaje de la fenomenología, más influyente de lo que pudiera parecer en la filosofía de Wittgenstein) que se corresponden con tales reglas, como "un cuadrado sólo puede tener cuatro lados iguales", "si algo es azul, no puede a la vez ser marrón".

Wittgenstein pasa así, como ha subrayado Conte, de la perspectiva física de la verdad o falsedad de los estados de cosas a la perspectiva fenomenológica del sentido o sinsentido de los estados de cosas, de la descripción de la estructura de los estados fenomenológicos de las cosas y sus propiedades espaciales, temporales y materiales. Lo relevante no es ya la sintaxis de las proposiciones, sino la sintaxis de los sistemas de proposiciones. El análisis teórico de las reglas lingüísticas (sintácticas y semánticas) deja de tener para él interés porque la relación entre una palabra y su significado no se da en la teoría, sino en la práctica, en los usos lingüísticos de la palabra, los cuales no siguen regla alguna. La técnica filosófica de los juegos del lenguaje sirve como terapia al librarnos de las confusiones filosóficas causadas por la consideración del lenguaje al margen de los contextos y actividades vitales, al margen de las formas de vida. Expresarse lingüísticamente es algo que entra dentro de una forma de vida, y según cómo sea ésta surgen variadísimos tipos de lenguaje, paralelos a los correspondientes juegos lingüísticos. El lenguaje no sólo sirve para representar la realidad, para describir, sino también para relatar, para hacer suposiciones, para plantear hipótesis, para enseñar, para representar teatro, para jugar, para cantar, para bromear, para traducir, para disculparse, para rogar, para orar, para saludar, para insultar, para blasfemar, para interrogar,.... y para prescribir (Wittgenstein, 1953).

Wittgenstein concentra sus esfuerzos en alertar sobre el riesgo de tratar de responder a la cuestión del significado de las palabras, que son a su juicio indefinibles. Sólo podemos conocer el significado de palabras que representan entidades factuales aprendiéndolo paulatinamente a través de definiciones ostensivas, a través de definiciones que no se refieren a la intensión o connotación del término, sino a su extensión o denotación, ya que consisten en mostrar una serie de ejemplos de objetos de los que puede afirmarse que tienen alguna relación con el término en cuestión. El estudio de los juegos lingüísticos es el estudio de formas primitivas de lenguaje o de lenguajes primitivos, no contaminados por complejos procesos intelectuales, y es a juicio de Wittgenstein muy útil para afrontar problemas como el de la naturaleza de los diferentes tipos de lenguaje: descriptivo, exhortativo, interrogativo, prescriptivo, etc. El principal error filosófico ha sido el de buscar la esencia o elemento común a todos los usos de un término para tratar de clarificar su significado, con lo que el filósofo ha ignorado las situaciones concretas, que son precisamente las que ayudan a comprender el uso del término. Los juegos lingüísticos no son por consiguiente investigaciones preparatorias para poder reglamentar correctamente el lenguaje, sino objetos de comparación que mediante semejanzas y desemejanzas precisan las condiciones de nuestro lenguaje. Con los juegos lingüísticos no se dice nada, incide Wittgenstein, no se trata de perfeccionar el siste- 
ma de reglas que rige el uso del lenguaje, sino que sólo se muestran técnicas para combatir las confusiones lingüísticas.

En la filosofía del segundo Wittgenstein las reglas constitutivas que definen las instituciones no son instrumentos de explicación ni de comprensión de la conducta humana, sino pautas para interpretar fenómenos institucionales, para interpretar fenómenos en el contexto de juegos lingüísticos (se puede decir que las reglas constitutivas de instituciones son, en palabras de Conte, instrumentos de interpretación eidográfica, de interpretación según el eidos que constituyen, pero no de comprensión idiográfica, de comprensión de la conducta en su individualidad). No se debe buscar entonces una explicación cuando simplemente debemos ver lo que sucede como protofenómeno, cuando sólo debemos decir que "se juega este juego lingüístico": "no se trata de explicar juegos lingüísticos a través de nuestras experiencias, sino de constatarlos"; es decir, de interpretar (eidográficamente) formas de vida, de constatar formas de vida que valen y cuentan en tanto que reflejos de las reglas constitutivas que les dan sentido (Wittgenstein, 1953, af. 654 y 655).

\section{El ordenamiento jurídico como sistema normativo}

Conte subraya que el ordenamiento jurídico no es una mera figura lineal, una mera secuencia de normas sin relación entre sí. El significado de cada norma jurídica no es independiente, sino dependiente del significado de las demás, con las que interactúa y se integra en un conjunto. Las normas de un ordenamiento se relacionan entre sí, y cada una de ellas se subordina a la norma fundamental, que, como cúspide de la pirámide normativa, es condición necesaria de validez de las restantes normas del ordenamiento.

Las normas jurídicas no están aisladas, sino que, como totalidad ordenada, constituyen un sistema. Desconocer el carácter sistemático del derecho es un error en el que se incurre cuando se desarrolla un análisis teórico sólo dirigido al estudio de las normas jurídicas y de los conceptos jurídicos en sí mismos, prescindiendo de la idea global del ordenamiento jurídico como sistema.

Desde tres perspectivas diferentes, la noción sistemática de ordenamiento puede para Conte cumplir la función metodológica de servir de instrumento de análisis jurídico:

a) En primer lugar, mediante la idea del ordenamiento jurídico como sistema se puede explicar la existencia del derecho. Por ejemplo, para el institucionalismo, el derecho existe en tanto que existe el ordenamiento jurídico, y el ordenamiento jurídico existe en tanto que existen las instituciones.

b) En segundo lugar, mediante la idea del ordenamiento jurídico como sistema se puede comprender qué es el derecho. Por ejemplo, para el normativismo, el derecho se define en términos de ordenamiento y no en términos de norma: no es que un ordenamiento sea jurídico por el hecho de ser un conjunto de normas jurídicas, sino que, al contrario, las normas son jurídicas por el hecho de formar un ordenamiento jurídico.

c) En tercer lugar, mediante la idea de ordenamiento jurídico como sistema se puede conocer lo que es derecho, lo que es jurídico. Por ejemplo, para determinados sectores del normativismo, 
mediante tal idea se puede definir el concepto de validez jurídica: la validez de una norma deriva, en el contexto del ordenamiento jurídico al que pertenece, y conforme al principio de legalidad, de la validez de otra norma superior, y así sucesivamente hasta llegar a la norma fundamental del ordenamiento.

El institucionalismo, resalta Conte, se enfrenta al problema de la existencia del derecho exigiendo tres condiciones: que exista una sociedad que sea el destinatario del derecho como ordenamiento; que exista una regulación de las relaciones intersubjetivas que sea el fin del derecho como ordenamiento; y que exista una organización que sea el medio o instrumento del derecho como ordenamiento.

Por su parte, el normativismo no se enfrenta al problema de la existencia del derecho, sino al problema de la definición del derecho y de la validez jurídica, concibiendo el ordenamiento jurídico como una pirámide normativa en cuya cúspide se halla la norma fundamental, de la que deriva la validez de todas las normas jerárquicamente estructuradas. A diferencia de los sistemas estáticos, en los que bajo la norma fundamental todas las normas están al mismo nivel jerárquico, los sistemas dinámicos como el jurídico se caracterizan por la pluralidad de escalones normativos. La validez jurídica de una norma no sólo depende (como en los sistemas estáticos) de la norma fundamental; depende también de las condiciones de validez puestas por las demás normas superiores a ella (Conte, 1965).

En los ordenamientos estáticos la norma fundamental es la única condición necesaria de validez, es condición necesaria y suficiente, pero en los ordenamientos dinámicos deben cumplirse además otras condiciones, y su contenido no predetermina el contenido de las normas que se subordinan a ella, del mismo modo que ninguna norma jurídica superior, aunque establezca las condiciones de validez de las normas inferiores, predetermina su contenido. Las normas jurídicas primarias se crean a través de actos de promulgación que cumplen las condiciones, personales y procedimentales, establecidas por las normas inmediatamente superiores, por normas que determinan quién posee competencia para promulgar normas primarias. Las normas de competencia se crean a través de actos que cumplen las condiciones establecidas por las normas de competencia de orden superior, por ejemplo de rango constitucional. Y las normas de competencia constitucionales se crean a través de actos que cumplen las condiciones establecidas por las normas que regulan la reforma constitucional, en la práctica superiores a las restantes normas constitucionales. La validez de cada norma depende directamente de la validez de la norma inmediatamente superior, e indirectamente de la existencia de la norma fundamental.

El rasgo principal de todo sistema jurídico es su unidad. Desde el punto de vista formal, la unidad significa totalidad jerárquica, significa imputabilidad de todas las normas a una única norma fundamental. La norma fundamental es el presupuesto jurídico fundamental que da sentido a todo el ordenamiento, que define las formas de conducta con relevancia normativa, que constituye la realidad jurídica. Sin embargo, la norma fundamental, al establecer que toda norma debe fundar su validez en una norma superior, establece paradójicamente su propia invalidez, ya que no existe ninguna norma superior 
a la norma fundamental. Una teoría de la validez basada en que toda norma debe fundar su validez en una norma superior se convertiría en aporía si la norma suprema no posee fundamento de validez, lo que sucesivamente provocaría la invalidez de todas las normas del ordenamiento.

Sólo la teoría de los tipos de Russell parece para Conte poder despejar las dudas sobre el carácter paradójico de la norma fundamental y las contradicciones de una teoría de la validez basada en ella. Más allá de la idea kelseniana de que la norma fundamental se presupone válida en tanto que hipótesis lógico-trascendental, no debería tomarse ni como válida ni como inválida, sino como definición de validez, como criterio para determinar si las restantes normas del ordenamiento son o no válidas. Siguiendo el símil de Hart, la norma fundamental, como la barra de platino que en un museo de París define lo que es la unidad "metro", es una pauta de medida: "mide" la validez o invalidez de las normas. Aunque sirve para medir cualquier distancia en metros, la barra de platino no se puede medir a sí misma porque no tiene la longitud de un metro, sino que es la longitud de un metro, y si al calentarse o enfriarse se agranda o empequeñece sigue siendo siempre un metro. La norma fundamental tampoco tiene validez, sino que es la validez, y si cambia seguirá siendo validez.

\section{Bibliografía}

Aarnio, Aulis, The Rational as Reasonable. Reidel, Dordrecht, 1987.

Alarcón Cabrera, Carlos, Normas y paradojas. Madrid, Tecnos, 1993.

Alchourrón, Carlos E. / Bulygin Eugenio, Normative Systems. Wien, New York, Springer-Verlag, 1971.
Alchourrón, Carlos E. / Bulygin, Eugenio, Análisis lógico y derecho. Madrid, Centro de estudios constitucionales, 1991.

Alexy, Robert, Teoría de la argumentación jurídica. Traducción castellana de Manuel Atienza e Isabel Espejo. Madrid, CEC, 1989.

Aristóteles, Ética a Nicómaco. Edición a cargo de Francisco Larroyo. México, Porrúa, 1982.

Austin, John,, Lectures on Jurisprudence. London, John Murray, 1885.

Austin, John Langshaw, How to Do Things with Words. London, Oxford University Press, 1962.

Azzoni, Giampaolo M., Validità semantica in deontica. "Rivista internazionale di filosofia del diritto", 69 (1992), pp. 166-177.

Bobbio, Norberto, Diritto e logica. "Rivista internazionale di filosofia del diritto", 39 (1962), pp. 11-45.

Capella Hernández, Juan R., El derecho como lenguaje. Barcelona, Ariel, 1968.

Carnelutti, Francesco, Teoria generale del diritto. Roma, Foro italiano, 1939.

Castañeda, Héctor-Neri, Un sistema general de lógica normativa. "Dianoia", 3 (1957), pp. 303-333.

Castignone, Silvana, La macchina del Diritto. Milano, Edizioni di Comunità, 1974.

Conte, Amedeo G., Un saggio filosofico sopra la logica deontica. "Rivista internazionale di filosofia del diritto", 42 (1965), pp. 564-577.

Conte, Amedeo G., Studio per una teoría della validità. "Rivista internazionale di filosofia del diritto", 47 (1970), pp. 331-354.

Conte, Amedeo G., Ricerca d'un paradosso deontico. "Rivista internazionale di filosofia del diritto", 51 (1974), pp. 481-511.

Conte, Amedeo G., Codici deontici. En: Intorno al "codice". Atti del terzo convegno 
della AISS Associazione italiana di studi semiotici (Pavia, 1975). Firenze, La Nuova Italia, 1976, pp. 13-25.

Conte, Amedeo G. / Hilpinen, Risto / Wright, Georg H. von (eds.), Deontische Logik und Semantik. Wiesbaden, Athenaion, 1977.

Conte, Amedeo G., Phénoménologie du langage déontique. In: Kalinowski, Georges / Selvaggi, Filippo (eds.), Les fondements logiques de la pensée normative. Roma, Editrice Università Gregoriana, 1985, pp. 179-193.

Conte, Amedeo G., Deontico vs. dianoetico. "Materiali per una storia della cultura giuridica", 16 (1986), pp. 489-494.

Conte, Amedeo G., Minima deontica. "Rivista internazionale di filosofia del diritto", 65 (1988), pp. 427-475.

Conte, Amedeo G., Regole costitutive in deontica. In: Febbrajo, Alberto (ed.), Filosofia del diritto e teoria politica. Milano, Giuffrè, 1990, pp. 207-250.

Conte, Amedeo G., Deon in Deontics. "Ratio Juris", 4 (1991), pp. 349-354.

Conte, Amedeo G., Deontica aristotelica. "Rivista internazionale di filosofia del diritto", 69 (1992), pp. 178-252.

Conte, Amedeo G. / Alarcón Cabrera, Carlos, Deóntica de la validez. Madrid, Tecnos, 1995.

Conte, Amedeo G. / Mazzarese, Tecla, Regole fondate su regole. "Nuova civiltà delle machine», 3 (1985), 1-2 (9-10), pp. 61-63.

Dworkin, Taking Rights Seriously. London, Duckworth, 1977.

Geiger, Theodor, Vorstudien zu einer Soziologie des Rechts. Munskgaard, Kobenhaven, 1947.

Hare, Richard M., The Language of Morals. London, University Press, 1952.

Hart, H., The Concept of Law. Oxford, Oxford University Press, 1961.
Hernández Marín, Rafael, Historia de la filosofía del derecho contemporánea. Madrid, Tecnos, 1986.

Hernández Marín, Rafael, Practical Logic and the Analysis of Legal Language. "Ratio Juris", 4 (1991), pp. 322-333.

Hierro, José S. P., Problemas del análisis del lenguaje moral. Madrid, Tecnos, 1970. Iturralde Sesma, Victoria, Sobre el silogismo judicial. "Anuario de filosofía del derecho”, 8 (1991), pp. 239-272.

Jorgensen, Jorgen, Imperativer og logik [Imperativos y lógica]. "Theoria”, 4, 1938, pp. 183-190.

Jorgensen, Jorgen, Imperatives and Logic. "Erkenntnis", 7 (1937-1938), pp. 288296.

Kalinowski, Jerzy, Essai su le caractère ontique du droit. "Revue de l'Université d'Ottawa», 34 (1964), pp. 81-99.

Kalinowski, Georges, Le problème de la vérité en morale et en droit. Lyon, Vitte, 1967.

Kant, Emmanuel, Fundamentación de la metafísica de las costumbres (1785), 1990. Traducción castellana de Luis Martínez de Velasco. Madrid, Espasa-Calpe.

Kelsen, Hans, Das Problem der Souveränität und die Theorie des Völkerrechts. Tubingen, Mohr, 1920.

Kelsen, Hans, Reine Rechtslehre. Wien, Deuticke, 1934.

Kelsen, Hans, General Theory of Law and State. Cambridge, Harvard University Press, 1945.

Kelsen, Hans, Recht und Logik. "Forum", 12 (1965), pp. 421-425 y 495-500.

Kelsen, Hans, Nochmals: Recht und Logik. "Neues Forum", 14 (1967), pp. 3940.

Kelsen, Hans / Klug, Ulrich, Rechtsnormen und Logische Analyse. Wien, Deuticke, 1981. 
Klug, Ulrich, Juristische Logik. Berlin, Springer, 1951.

Mazzarese, Tecla, Logica deontica e linguaggio giuridico. Padova, Cedam, 1989. Oppenheim, Félix, Lenguaje y ciencia del derecho. Fondo de cultura económica, México, 1944.

Olivecrona, Karl, Law as Fact. London, Oxford University Press, 1939.

Perelman, Chaim, Tratado de la argumentación. La nueva retórica, Traducción castellana de Julia Sevilla. Madrid, Gredos, 1989.

Prior, Arthur N., Logic and the Basis of Ethics. Oxford, Clarendon Press, 1949.

Rawls, John, Two concept of rules. "The Philosophical Review", 64 (1955), pp. 3-32.

Ross, Alf, Imperatives and Logic. "Theoria", 7 (1941), pp. 53-71.

Ross, Alf, Directives and Norms. London, Routledge, 1968.

Sánchez-Mazas, Miguel, Cálculo de las normas. Barcelona, Ariel, 1973.

Scarpelli, Uberto, Contributo alla semantica del linguaggio normativo. Torino, Memoria dell'Accademia delle scienze di Torino, 1959 ( $1^{\text {a }}$ ed.); Milano, Giuffrè, 1985 ( $2^{\mathrm{a}}$ ed.).

Scarpelli, Uberto / Di Lucia, Paolo (eds.), /l linguaggio del diritto. Milano, LED, 1994.

Searle, John R., Speech Acts. London, Cambridge University Press, 1969.

Wittgenstein, Ludwig, Philosophical Investigations. Oxford, Blackell, 1953,

Wright, Georg H. von, Deontic Logic. "Mind", 60 (1951), pp. 1-15.

Wright, Georg H. von, An Essay in Modal Logic. Amsterdam, North-Holland, 1951. Wright, Georg H. von, On the Logic of Negation. Kobenhavn, Munksgaard, 1959.
Wright, Georg H. von, Norm and Action. London, Routledge and Kegan Paul, 1963.

Wright, Georg H. von, Deontic Logic and the General Theory of Conditions. "Crítica", 2 (1968), pp. 3-25.

Wright, Georg H. von, An Essay in Deontic Logic and the General Theory of Action. Amsterdam, North-Holland, 1968.

Wright, Georg H. von, Deontic Logic and the Ontology of Norms. In: Akten des XIV Internationalen Kongresses für Philosophie (Wien, 1968). Wien, Herder, 1968, vol. 2, pp. 304-311.

Wright, Georg H. von, Deontic Logic Revisited. "Rechstheorie", 4 (1973), pp. 3746.

Wright, Georg H. von, On the Logic and Ontology of Norms. In: Davis, John W. (ed.), Philosophical Logic. Dordrecht, Reidel, 1981, pp. 89-107.

Wright, Georg H. von, Norms, Truth and Logic. In: Wright, Georg Henrik von, Practical Reason. Oxford, Blackwell, 1983, pp. 130-209.

Wright, Georg H. von, Is There a Logic of Norms? "Ratio Juris", 4 (1991), pp. 265283.

Wright, Georg H. von, On Conditional Obligation. "Särtryck ur juridisk tidskrift", 1 (1994-1995), pp. 1-7.

Wright, Georg H. von, Six Essays in Philosophical Logic. Helsinki, Societas Philosophica Fennica (vol. 60), 1996. 